\title{
GÉNERO Y TORTURA. SIMONE DE BEAUVOIR Y GISÈLE HALIMI ANTE EL CASO DE DJAMILA BOUPACHA*
}

\author{
GENDER AND TORTURE. \\ SIMONE DE BEAUVOIR AND GISÈLE HALIMI \\ REGARDING THE CASE OF DJAMILA BOUPACHA
}

\author{
EMILIA BeA PéRez \\ Universitat de València
}

Fecha de recepción: 5-9-20

Fecha de aceptación: 11-1-21

Resumen: La primera denuncia de violencia sexual como práctica de tortura en la guerra de Argelia se debe a Djamila Boupacha. Su causa fue defendida ante los tribunales argelinos y franceses por la abogada feminista, Gisèle Halimi, y tuvo una gran repercusión pública gracias al apoyo de Simone de Beauvoir y a la movilización de un comité conformado sobre todo por mujeres, en el intento de dar relevancia política y jurídica a un asunto destinado a permanecer oculto. El trabajo valora el enfoque anticolonial y antipatriarcal con que se afrontó el caso, analiza todo el proceso judicial y llama la atención sobre aquellos elementos que prefiguran la evolución del derecho hacia una justicia de género.

Abstract: The first complaint about sexual violence as a form of torture in the Algerian war concerns Djamila Boupacha. Her case was defended in the Algerian and French courts by the feminist lawyer Gisèle Halimi, and it had a massive public impact thanks to the support of Simone de Beauvoir and the mobilisation of a committee composed mainly of women, which sought to raise the political and legal profile of a matter which was destined to remain hidden. The paper assesses the anti-colonial and anti-patriarchal stance on which it is based,

* $\quad$ El presente trabajo se ha realizado en el marco del Proyecto PROMETEO/2018/156 "Seguridad internacional y europea: de la prevención de conflictos armados a las estrategias para la construcción de una ciudadanía inclusiva y plural", de la Generalitat Valenciana, y del Proyecto I+D+I PGC2018-094463-B-100 (MCIU/AEI/FEDER,UE) "Vulnerabilidad en el pensamiento filosófico femenino. Contribuciones al debate sobre emergencias presentes".

ISSN: 1133-0937

DERECHOS Y LIBERTADES

DOI: https://doi.org/10.20318/dyl.2021.6102

Número 45, Época II, junio 2021, pp. 57-98 
analyses the entire judicial process, and highlights the issues that herald the evolution of law towards gender justice.

Palabras clave: tortura, género, violencia sexual, violación, guerra Keywords: torture, gender, sexual violence, rape, war

\section{PROCESO A LA TORTURA. ENTRE LA REPRESIÓN Y LA RESISTENCIA POLÍTICA}

En el presente trabajo vamos a tratar la relación entre género y tortura ciñéndonos a un caso que resulta precursor a la hora de establecer los términos de esta relación, entre otras razones porque puso en contacto a dos de las principales representantes del pensamiento feminista, Simone de Beauvoir y Gisèle Halimi, con una mujer torturada, Djamila Boupacha, cuyo tormento, sufrido en la guerra de Argelia ${ }^{1}$, es todo un símbolo de cómo el cuerpo de la mujer puede ser el lugar de la represión y al mismo tiempo el de la resistencia política. El cruce entre experiencias aparentemente tan alejadas como la de una intelectual existencialista ya en su tiempo de renombre internacional, la de una abogada de gran prestigio y relevancia pública, y la de una anónima activista del Frente de Liberación Nacional (FLN) argelino, puede convertirse en el lugar privilegiado para pensar las raíces de la violencia contra la mujer y sus profundas conexiones con las dinámicas del poder.

En este cruce de experiencias, las tres interlocutoras tienen un papel igualmente relevante, aunque distinto, a la hora de formar parte de un proceso que con razón ha podido definirse como el último gran affaire de la guerra de Argelia ${ }^{2}$. La mediadora de este encuentro fue Gisèle Halimi, que acudió a defender a Djamila Boupacha ante los tribunales argelinos y, dada la naturaleza esencialmente política tanto del acto terrorista del que la joven militante había sido acusada como de la tortura que le había sido infligida, estableció una estrategia en la que la movilización de la opinión pública sería un imprescindible apoyo a la sustanciación jurídica del caso. Nadie mejor

1 Solo a partir de 1999 (ley de 18 de octubre) se utiliza oficialmente este término ya que, si bien desde el lado argelino se habla muy pronto de guerra -de liberación nacional o de independencia-, en el lado francés se utilizan términos como "los acontecimientos de Argelia" o "las acciones de pacificación". Esta "guerra sin nombre", se extendió de 1954 a 1962.

2 Véase V. CODACCIONI, “(Dé)Politisation du genre et des questions sexuelles dans un procès politique en contexte colonial: le viol, le procès et l'affaire", Nouvelles Questions Féministes, vol. 29, 2010/1, pp. 32-45. 
que Simone de Beauvoir para cumplir este papel concienciador, pues nadie en aquel momento representaba con más autoridad conjuntamente la causa anticolonialista y la causa de las mujeres.

\subsection{La abogada Gisèle Halimi: ejercicio profesional y actividad pública}

El hermano de Djamila Boupacha, internado en el campo de Bossuet (Orán), fue quien consiguió contactar por carta, fechada el 29 de marzo de 1960, con Gisèle Halimi, que desde hacía seis años defendía a militantes del Frente de Liberación Nacional ante los tribunales militares de Argelia. Nacida el 27 de julio de 1927 en Túnez en el seno de una familia judía, Halimi (fallecida el 28 de julio de 2020 cuando redactábamos este artículo) reflexiona sobre sus orígenes y relata sus experiencias en un libro autobiográfico titulado La lait de l'oranger ${ }^{3}$. Feminista de modo casi instintivo y "embrionario" en "un medio en el que, sin alternativa, las jóvenes de este país no tenían más remedio que someterse", de forma "global, por la tradición, por la educación y por la ley" " ${ }^{4}$, fundó un pequeño movimiento en el que reivindicar con otras mujeres "la necesidad de estudiar y de rechazar la injusticia de nuestro destino" ${ }^{\prime \prime}$. Sin embargo, frente a la situación de la mayoría de las mujeres tunecinas ${ }^{6}$, a Gisèle Halimi se le abren las puertas de una ansiada liberación personal cuando, acompañada por la lectura de El segundo sexo, marcha a París para estudiar derecho y filosofía en la Sorbona7 . Lejos del olvido de sus raíces y convicciones previas, su ejercicio profesional y su actividad pública estarán marcados por su compromiso con aquellas causas que

3 G. HALIMI, La lait de l'oranger, Gallimard, Paris, 1988. La narración se extiende hasta la muerte de su padre a finales de 1976. Otras obras de carácter autobiográfico de la autora son: La cause des femmes, Grasset, Paris, 1973 y Une embellie perdue, Gallimard, Paris, 1995. Su apellido familiar era Taïeb, pero, a pesar del divorcio y de volverse a casar con Claude Faux, mantuvo el apellido de su marido Paul Halimi. Sobre sus orígenes dice que "escoltada por rabinos en un país islámico" heredó tradiciones contradictorias (La lait de l'oranger, p. 351). Julien Murphy relaciona esta situación con la de otras escritoras como Assia Djebar, Marie Cardinal o Hélène Cixous, cuyas identidades culturales son difíciles de definir. J. MURPHY, "Beauvoir and the Algerian War: Toward a Postcolonial Ethics", en M. A. SIMONS (ed.), Feminist Interpretations of Simone de Beauvoir, The Pennsylvania State University, 1995, pp. 263-297, p. 291.

4 G. HALIMI, La lait de l'oranger, cit., pp. 107-108.

5 Ibid., p. 111.

6 Ibid., p. 109.

7 Ibid., p. 111. 
considera justas, desde los procesos políticos en Argelia, como el de Badèche Ben Hamdi o el de El Halia ${ }^{8}$, a los procesos relacionados con los derechos de las mujeres como el juicio por aborto de Bobigny ${ }^{9}$ o por violación en Aix-enProvence $^{10}$, pasando por el Tribunal Russell o el proceso de Burgos ${ }^{11}$, además de la fundación del colectivo feminista Choisir la cause des femmes o su elección como miembro de la Asamblea Nacional de Francia.

A lo largo de su itinerario vital, sus opciones estuvieron marcadas no solo por el compromiso firme, sino también, y como consecuencia de ello, por la polémica e, incluso, por reacciones muy adversas. En los años dedicados a defender a los militantes del FLN sufrió los ataques de la prensa colonialista y las amenazas de la OAS (Organización Armada Secreta), más de una vez fue expulsada de la Sala y soportó los reproches de los jueces tachándola de injuriar la bandera francesa y de olvidar su juramento: "es el pan de cada día de los pocos abogados habitualmente presentes en los procesos políticos de Argelia" 12; una presencia ineludible dado que "sin nosotros probablemente no hubieran tenido defensa pues los abogados argelinos habían sido detenidos, deportados o internados en campos" ${ }^{13}$.

8 A este proceso le dedica tres capítulos de La lait de l'oranger. Ante la masacre producida por un atentado terrorista el 20 de agosto de 1955, que es "una de las realidades más insoportables de esta guerra" (p.174), Gisèle Halimi se pregunta si para un abogado hay algo "indefendible" (p. 131). Por fin asume la defensa de los cuarenta y cuatro acusados, a los que se presenta "como culpables dado que los culpables han desaparecido, añadiéndose, así, otro crimen al crimen" (p.174).

9 Defendió a Michèle Chevalier, acusada de haber ayudado a abortar a su hija MarieClaire de 16 años que había sido violada. El juicio se celebró en 1972 y la movilización que despertó tuvo una influencia decisiva en la despenalización del aborto en Francia (conocida como la ley Veil, de 1975). Véase, Avortement: une loi en procès. L'affaire de Bobigny, pref. de Simone de Beauvoir, Gallimard, Paris, 1973.

10 Sobre este caso, en el que se logró condenar a los tres autores de la violación de dos jóvenes turistas belgas y que influyó directamente en la reforma legislativa francesa que llevó en 1980 a convertir la violación en un crimen castigado con 15 años de reclusión, véase S. PETRILLI y G. HALIMI, Viol. Le procès d'Aix-en-Provence. Compte rendu intégral des débats, Gallimard, Paris, 1978.

11 Véase G. HALIMI, El proceso de Burgos, pról. Jean-Paul Sartre, trad. M. Rivera, Monte Ávila, Caracas, 1972. Asistió al juicio, en diciembre de 1970, como representante de la Federación Internacional de Derechos Humanos. Antes había estado en España en 1962, en solidaridad con los mineros de Asturias, y en 1964, con motivo de las detenciones de estudiantes. Volvió en 1974, para defender a Eva Forest.

12 G. HALLIMI, La lait de l'oranger, cit., p.116.

13 Véase http://nadjet-criducoeur.blogspot.com/2008/11/affaire-de-djamila-boupacha-gisle. html.1/11/2008. 
Esta intensa actividad duró casi una década hasta los Acuerdos de Evian de 1962, que pusieron fin a la guerra de Argelia decretando una amplia amnistía de la que se beneficiarían los dos bandos. El año 1957 fue muy significativo en lo que respecta al importante papel que los abogados jugarían como voces de alerta sobre la situación argelina. Entre otros casos que llegaron a los medios de comunicación, podemos señalar la condena a muerte de dos mineros de 16 y 17 años acusados de terrorismo, a los que finalmente se les conmutó por cadena perpetua. La misma pena, también por actos terroristas, pesaría sobre Djamila Bouazza, Jacqueline Guerroudj y Djamila Bouhired ${ }^{14}$, cuya aparición en la prensa francesa era un primer reconocimiento de la efectividad de una militancia femenina en Argelia, lo que propiciaría una primera lectura de los procesos desde una perspectiva de género ${ }^{15}$. El controvertido abogado Jacques Vergès fue el defensor de la última de las activistas citadas, implicando al periodista Georges Arnaud en la firma de un manifiesto a su favor titulado "Pour Djamila Bouhired", antecedente del título del artículo que Simone de Beauvoir publicará en Le Monde tres años después para sacar a la luz pública el caso de Djamila Boupacha, como veremos.

Si bien este manifiesto cumpliría una función relevante en la denuncia de la represión y los abusos por parte del ejército francés en Argelia, el libro La Question de Henri Alleg ${ }^{16}$ sería el instrumento más potente para poner al descubierto la tortura practicada en el contexto de la guerra. Un documento de la experiencia de los maltratos y tormentos que Alleg, periodista franco-argelino director del periódico Alger républicain, sufriría en su propia carne desde su detención en ese fatídico año de 1957, en el que también se data la desaparición en un interrogatorio del joven matemático Maurice Audin, independentista miembro del partido comunista argelino. La función de los juristas se vería reforzada por la de los intelectuales, y en estos casos, en concreto, por la de figuras tan significativas en la vida cultural francesa como Jean-Paul Sartre y Pierre Vidal-Naquet ${ }^{17}$.

14 Simone de Beauvoir testificó a favor de Jacqueline Guerroudj, que había sido alumna suya en Ruan. Véase, S. de BEAUVOIR, La force des choses, Gallimard, Paris, 1963. Citaremos la traducción La fuerza de las cosas, trad. E. de Olaso, Edhasa, Barcelona, 1982, p. 449.

15 Véase V. CODACCIONI, “(Dé)Politisation du genre et des questions sexuelles dans un procès politique en contexte colonial: le viol, le procès et l'affaire”, cit., p. 33 .

16 H. ALLEG, La Question, pról. J.P. Sartre, Les éditions de Minuit, Paris, 1958. El texto de Sartre, "Une victoire”, merece ser leído con atención. El libro fue secuestrado por el gobierno francés, lo que generó una amplia reacción.

17 Además de otros libros importantes del autor sobre la práctica de la tortura en Argelia, véase P. VIDAL-NAQUET, L'affaire Audin, Les éditions de Minuit, Paris, 1958. El 
En mayo de 1958, con ocasión de una visita a sus clientes en la prisión de Barberousse y por encargo del colega Léo Matarasso, Gisèle Halimi pide permiso al juez para visitar a Henri Alleg y, a pesar de los impedimentos, finalmente puede escuchar su desesperada súplica de ayuda ${ }^{18}$. Entonces recuerda una entrevista en esa misma cárcel con el general de paracaidistas Jacques Massu, a quien le precedía y le acompañará siempre la fama de participar y avalar prácticas de tortura. Ante Massu, la abogada irrespectueuse ${ }^{19}$ califica de "arbitrario", de "inhumano" y de "ilegal" su proceder. El general, tras un silencio, le dice: "Yo sé que usted condena la tortura... de acuerdo... pero ¿usted encuentra aceptable que los niños sean despedazados en un autobús por las bombas del Frente de Liberación Nacional... usted, una madre de familia?". Halimi comprende que Massu ha aceptado mantener esta conversación con ella para "comunicarle las grandes líneas de sus teorías sobre la tortura; incluso para contrastarlas con alguien que las ha denunciado sin cesar". La prueba de ello son las palabras que le dirige en tono enfático: "Si usted condena estos atentados ciegos, usted debe comprender que lo importante en esta lucha es la información"; "usted habla de sufrimientos, de atrocidades...todo tonterías". Y también recuerda que el general, subiéndose la manga de la camisa, le enseñó el brazo y añadió: "Yo la he probado sobre mí mismo, la tortura... con electrodos... y no es nada de todo eso"; "es psicológico, eso es todo, les da miedo y les hace hablar... créame! jes eficaz la tortura!”. Halimi confiesa que en aquel momento se sintió nadando en el absurdo y que tan solo acertó a repetir que la tortura debe ser condenada de forma absoluta ${ }^{20}$.

El caso de Djamila Boupacha es un paso más en la creciente apertura al espacio público de una realidad que permanece oculta tras los muros del Estado colonial pero que, como se deduce de este diálogo, pretende incluso justificarse cuando sus grietas comienzan a hacerse visibles. Un paso que, apoyándose en la experiencia anterior, es decir, en otros procesos y alegatos contra las confesiones forzadas, resultó decisivo para Gisèle Halimi porque le hizo descubrir, y mostrar ante la opinión pública, aspectos que esas grietas en el sistema permitían vislumbrar y que eran desconocidos hasta entonces.

presidente E. Macron reconoció públicamente en 2018 el papel del Estado en la muerte de Maurice Audin y pidió perdón a su viuda.

18 G. HALIMI, La lait de l'oranger, cit., pp. 273-274.

19 Título de uno de sus libros: G. HALIMI, Avocate irrespectueuse, Plon, Paris, 2002.

20 G. HALIMI, La lait de l'oranger, cit., pp. 275-276. J MASSU, autor de La Vraie Bataille d'Alger, Rocher, 1997, en una entrevista en Le Monde, el 22 de junio de 2000, por primera vez lamentó esta práctica. 
El asunto Boupacha resulta novedoso sobre todo porque se trata de la primera publicitación, en forma de denuncia, de algo que estaba llamado a quedar encerrado en la esfera más íntima: la violación como acto de tortura. Que una mujer a finales de los años cincuenta, y máxime siendo musulmana y virgen, declarara públicamente haber sido violada, resultaba casi inconcebible pues rompía el marco en el que se encuadraba su capacidad de hablar sobre sí misma y de comunicarse con los demás, lo que a la larga llevaría a replantear el modo de entender y de combatir la violencia sexual y de género.

\subsection{Djamila Boupacha: "En este país que es nuestro"}

En el primer encuentro entre Gisèle Halimi y Djamila Boupacha, la militante de tan solo veintidós años relató su experiencia traumática con gran sencillez. La abogada, enfrentándose "a la arbitrariedad de los permisos de viaje" ${ }^{21}$, había logrado llegar a Argel con una mínima antelación respecto a la vista ante el tribunal militar, convocada para la mañana del 18 de mayo de 1960, en que se juzgaría a Djamila tras confesar que había puesto una bomba, desactivada antes de explotar, en la Brasserie des Facultés de Argel el 27 de septiembre de 1959 y haber sido inculpada por pertenencia a organización criminal y por tentativa de homicidio, delitos que eran castigados con pena de muerte. Mientras esperaba en el locutorio de mujeres de la cárcel de Barberousse, Halimi se preguntaba cómo sería esa joven que había resistido a todas las presiones negándose a suprimir las dos últimas frases de su declaración: "Pido que me vea un médico. He sido torturada" ${ }^{22}$. Iniciada la conversación, Djamila contestaba brevemente, sin pasión, a las preguntas de la abogada, hasta el instante en que alzó la voz para decir que era una agente del FLN dispuesta a morir por la independencia de Argelia. Luego se desgarró, dijo que lo había confesado todo, y con una voz entrecortada, casi sollozante, que le habían hecho daño, "tanto daño" ${ }^{23}$. Detenida violentamente por las fuerzas del orden en su casa, junto a su padre y su cuñado, la noche del 10 al 11 de febrero de $1960^{24}$, había sufrido desde ese día, en el cuartel militar de

21 S. de BEAUVOIR y G. HALIMI, Djamila Boupacha, Gallimard, Paris, 1962. Citaremos la traducción al castellano, Djamila Boupacha. Proceso a la tortura, trad. de N. Petit, Seix Barral, Barcelona, 1963, p. 24.

22 Ibid., p. 28.

23 Ibid., p. 29.

24 Véase el relato completo en la biografía de Khalfa MAMERI Djamila Boupacha. L'inoubliable héroïne de la guerre d'Algérie, Thala éditions, Alger, 2013 (formato Kindle). 
El Biar y en Hussein Dey, terribles maltratos y humillaciones como la rotura de una costilla a patadas, la vejación verbal mientras permanecía desnuda atada a un sillón, la aplicación de electrodos y las quemaduras de cigarrillo en los lugares más sensibles y más íntimos de su cuerpo, y el juego de la báscula en una bañera, atada de pies y manos y colgada como una pieza de caza. De todos los ultrajes sufridos, el más atroz y denigrante fue la penetración en la vagina del gollete de una botella de cerveza, que los torturadores habían vaciado escupiendo sobre su cuerpo, lo que le produjo una gran hemorragia y la mantuvo inconsciente durante dos días ${ }^{25}$.

Gisèle Halimi queda conmocionada por el relato de la tortura de Djamila Boupacha, a pesar de estar acostumbrada a descripciones de este tipo de tormentos. Siente una gran indignación ante una mujer abandonada día y noche, durante semanas, "a unos hombres a los que la certeza de la impunidad hacía más monstruosos todavía", y a los que "entre tanto, en París, se les condecoraba con la Legión de Honor" ${ }^{26}$. Indignación unida a la ternura despertada por las palabras de despedida: “Mis padres no lo saben. Quiero decir que lo saben, pero no lo saben todo... lo de la botella no lo saben. No les he dicho nada. Es demasiado grave para nosotros". Y lo que sería su máxima preocupación: "Ya no sé si soy doncella... ¿Entiendes? Me había desmayado, y me salió sangre, cuando me bajaron a la celda". A raíz de estas confidencias, empieza a fraguarse un vínculo de amistad: “¿Tú que crees? ¿Qué ya no soy doncella? Dímelo sinceramente... ¿Qué crees?" La joven que, como el resto de detenidas y detenidos políticos, ayunaba durante todo el día, no da muestras de debilidad sino de una gran firmeza en su reiterada súplica, ligada al temor de la pérdida de la virginidad: "tiene que verme un médico" 27.

La relación de afecto entre abogada y clienta, que surgió en esta primera entrevista, influyó poderosamente en la convicción compartida de que la agresión sexual padecida en los interrogatorios no podía ser silenciada. Como recuerda Vanessa Codaccioni, será la propia Gisèle Halimi quien declararía años más tarde que los lazos emocionales entre ambas serían la clave de la excepcionalidad de este caso: "Si se quiere comprender la historia de Djamila Boupacha, hay que comprender el vínculo que se estableció entre

25 La descripción detallada del "suplicio" padecido se encuentra en el capítulo así titulado dentro del libro S. de BEAUVOIR y G. HALIMI, Djamila Boupacha. Proceso a la tortura, cit., pp. 35-48.

26 Ibid., p. 32.

27 Ibid., p. 47. 
nosotras dos. Yo creo que ella quedó perturbada por mi perturbación [...] Debí aparecer ante ella como un ser tan conmovido que me convertí en alguien muy próximo" ${ }^{28}$. De algún modo, Djamila Boupacha representaba "la integridad del cuerpo de la mujer, su respeto, su independencia, su autonomía, su compromiso político [...] Ella mostraba que el coraje, la resistencia, el compromiso de las mujeres podía equivaler o incluso superar al de los hombres en contextos difíciles, porque ella era musulmana, porque era creyente, porque había sido violada, pues todo esto era muy importante, y también el hecho de que las torturas que había sufrido fueran torturas que tenían el objetivo de atacar su dignidad como mujer. La violación no era lo mismo que las bastonadas en las plantas de los pies" ${ }^{29}$. Todas las causas que Halimi dice alimentar desde siempre -la causa de las mujeres, los derechos humanos, la lucha contra la tortura y el anticolonialismo- están aquí presentes.

Antes de la vista, Halimi solicita al Fiscal general de Argel, Robert Schmelk, que el proceso sea aplazado por falta de tiempo para preparar la defensa y le anuncia la interposición de una querella por secuestro y torturas. Ante la pregunta sobre si Djamila puso la bomba, la abogada responde: "No lo sé. Es una cuestión que para mí no tiene importancia, ya que, culpable o no, es una militante argelina a quien yo defendería de todas formas" ${ }^{30}$. En una nueva visita a la cárcel, Djamila le hace un pequeño relato de su implicación en el FLN, que en principio era tan solo de simpatía pues trabajaba en prácticas en un hospital y no quería disiparse de sus estudios. Sin embargo, a partir del momento en que ninguna musulmana logra entrar en nómina, toma conciencia de que las estructuras anacrónicas y

28 Entrevista con Gisèle Halimi el 9 de julio de 2008, citada por V. CODACCIONI, “(Dé) Politisation du genre et des questions sexuelles dans un procès politique en contexte colonial: le viol, le procès et l'affaire", cit., p. 35. Un vínculo emocional que se prolonga a las relaciones entre las dos familias.

29 Ibid., p. 36.

30 Ibid., p. 50. Khalfa MAMERI en su biografía Djamila Boupacha. L'inoubliable héroïne de la guerre d'Algérie, cit., recuerda haber oído decir claramente a Djamila en un encuentro el 30 de marzo de 2013 que ella se preparaba para colocar una "segunda bomba", y que reconoció espontáneamente en una foto a quien le remitió la bomba de la brasserie. En una entrevista en El Djeich. Revue mensuelle de l'Armée nationale populaire, núm. 652, 2017, la propia Djamila afirma: "En este contexto, dado que la revolución había movilizado todos los medios para encontrar eco en la opinión pública francesa e internacional y estrechar el cerco al ocupante, fui encargada de poner bombas en los lugares frecuentados por los colonos y otras operaciones, la última de las cuales tuvo lugar en 1959 cerca de la Facultad central”, p. 53. Véanse también las declaraciones recogidas en Le Grand Soir el 20/12/2013: https://www.legrandsoir.info/djamila-boupacha-heroine-de-la-guerre-de-liberation-femme-sans-peur-dame-de-coeur.html

ISSN: 1133-0937

DOI: https://doi.org/10.20318/dyl.2021.6102
DERECHOS Y LIBERTADES

Número 45, Época II, junio 2021, pp. 57-98 
discriminatorias "en este país que es nuestro", pero en el que "todo es para los franceses" ${ }^{31}$, nos impiden, irremediablemente, avanzar y ser libres. Es entonces cuando, influida principalmente por el patriotismo de su familia, empieza a colaborar en la lucha política a través de robos de medicamentos para los muyahidines, enlaces, misiones de información, y en alguna ocasión escondiendo en su casa, e incluso en su habitación, a responsables del maquis.

En el último momento, Halimi consigue el aplazamiento del juicio, lo que, según afirma, le permitirá hacer que, de regreso a París, "estalle el escándalo" 32 . Su estrategia de defensa consistirá en demostrar que las confesiones han sido arrancadas bajo tortura y, así, evitar la condena a muerte de su clienta por sus cargos de terrorismo y lograr la correlativa imputación de los torturadores. Para todo ello era imprescindible conseguir que el proceso se trasladara a Francia, pues la promulgación del decreto n ${ }^{\circ}$ 60-118, de 1960, que instituyó un régimen especial de jurisdicción militar para los juicios relacionados con la seguridad nacional, creaba en Argelia un contexto jurídico muy alejado de los principios del Estado de Derecho. En un artículo publicado en Les Temps Modernes ${ }^{33}$, Halimi se suma a la crítica capitaneada por Jacques Vergès, Michel Zavarian y Maurice Courrégé, autores de Le droit et la colère ${ }^{34}$.

En esta situación, a la vuelta de Argel y dado que se había señalado el 17 de junio como fecha de la próxima audiencia ante el tribunal militar, había que actuar rápidamente. La tortura infligida a Djamila era un "crimen particularmente atroz e inexcusable" y "toda Francia tenía que saberlo. Era preciso por ella, por los argelinos, por nosotros, por nuestros silencios y nuestras cobardías, por nuestro honor" y "habrá que gritar muy fuerte" 35 . Halimi escribe al general De Gaulle y a las máximas autoridades de la República. También se dirige a Daniel Mayer, presidente de la Liga de los Derechos del Hombre, y a François Mauriac, con quien había colaborado en alguna ocasión pero que en este caso escribió una nota en su sección de L'Express que ella consideró decepcionante, por sus reticencias y ambigüedades.

\footnotetext{
31 S. de BEAUVOIR y G. HALIMI, Djamila Boupacha. Proceso a la tortura, cit., p. 57.

32 Ibid., p. 63.

33 G. HALIMI, “D’Henri Alleg à Djamila Boupacha”, núm. 171, junio de 1960.

34 Éditions de Minuit, Paris, 1960.

35 S. de BEAUVOIR y G. HALIMI, Djamila Boupacha. Proceso a la tortura, cit., p.31.
} 


\subsection{Simone de Beauvoir: anticolonialismo y crisis de identidad}

Estaba convencida de que Simone de Beauvoir respondería de un modo mucho más claro y contundente. Se habían conocido en un acto de campaña por el no en el referéndum constitucional de 28 de septiembre de 1958, al que Simone de Beauvoir acudió acompañada por Sartre ${ }^{36}$. Halimi se sientió abrumada cuando Simone de Beauvoir, "la liberadora", alguien muy importante para ella y para su generación, le dijo admirarla por ser una joven activa y comprometida. La abogada respondió a sus preguntas sobre su profesión, sobre Argelia, y confiesa que se puso a temblar "al ver una comunión de ideas entre las dos casi perfecta" ${ }^{37}$. Sin embargo, aunque desde el primer encuentro Beauvoir fue uno de sus "referentes esenciales", "sin poderlo explicar" dice sentir una carencia: "esperaba a una mujer de combate y descubrí cada vez más a una entomóloga" ${ }^{38}$. Todo estaba programado: los horarios, los ritmos de los encuentros, los temas a tratar.

Cuando Gisèle Halimi se puso en contacto con Simone de Beauvoir para contarle el caso de Djamila Boupacha, como era previsible, se mostró absolutamente disponible a la hora de "buscar, las dos juntas, el medio radical de provocar las reacciones" ${ }^{\prime 39}$. El primer paso sería publicar un artículo en Le Monde para "arrancar brutalmente a los franceses de su confortable indiferencia sobre la cuestión argelina" ${ }^{40}$ y conseguir un nuevo aplazamiento del juicio. A la hora de la publicación, las gestiones con Robert Gauthier, redactor jefe del diario, fueron difíciles pues nada más recibir el artículo telefonea a Beauvoir para decirle que tienen muy malas referencias de Djamila Boupacha: "un alto funcionario, que está muy al tanto, nos asegura que hay graves cargos contra ella"; a lo que la autora responde: "eso no justifica que le hayan metido una botella ya sabe dónde" ${ }^{41}$. Además, Gauthier intenta que sustituya la palabra "vagina" por "vientre" y la frase "Djamila era virgen" por una perífrasis. Ante la negativa, se decide imprimir estas palabras entre paréntesis.

36 En sus memorias, La lait de l'oranger, le dedica el capítulo titulado "Le petit homme" (pp. 367-382). Gisèle Halimi se convertiría en abogada de Sartre y le profesaría una indefectible estima.

$37 \quad$ Ibid., p. 347.

38 Ibid., p 348. El capítulo dedicado a Beauvoir en la autobiografía se titula "El Castor" (apodo con el que siempre se la conoció, procedente de un juego de sonidos entre su apellido y la palabra beaver, castor en inglés), pp. 345-366.

39 S. de BEAUVOIR y G. HALIMI, Djamila Boupacha. Proceso a la tortura, cit., p. 70.

40 Ibid.

41 S. de BEAUVOIR, La fuerza de las cosas, cit., p. 584. 
El artículo de Simone de Beauvoir aparecerá en Le Monde el día 2 de junio de 1960 bajo el título "Pour Djamila Boupacha”, recordando al manifiesto en pro de Djamila Bouhired. Su impacto en la opinión pública fue inmediato, la edición publicada en Argel sería incautada y se recibieron cartas a favor o en contra tanto en la redacción del periódico como a la atención de Gisèle Halimi, y no solo de Francia sino de diferentes países del mundo. Como observa Julien Murphy, "semejante censura y atención fueron bastante extraordinarias. La autora de El segundo sexo aborda el caso de una mujer rebelde; una mujer africana rebelde, era demasiado para el establishment francés" ${ }^{42}$. El inicio del artículo tiene una gran fuerza expresiva: “Lo más escandaloso del escándalo es que uno se acostumbra a él. Parece sin embargo imposible que la opinión permanezca indiferente ante la tragedia que está viviendo una joven de veintidós años, Djamila Boupacha" ${ }^{43}$. A continuación, se relata la situación de la activista, obligada a confesar bajo tortura y obstaculizado el ejercicio de su derecho a la defensa, y se señala que, aunque "ya no está en poder de nadie borrar los tormentos que le fueron infligidos ni los que sufrieron su padre y su cuñado, todavía se puede detener la marcha de la injusticia. Se puede y se debe retrasar el proceso hasta que se hayan elucidado las circunstancias en las que Djamila habló" ${ }^{44}$. Simone de Beauvoir interpela directamente al gobierno de De Gaulle, que debe asegurar la protección de los testigos y castigar a los torturadores, y que, si renunciara a cumplir con sus obligaciones, "con esta abdicación, traicionaría a Francia entera [...] Cuando los dirigentes de un país consienten en que se cometan crímenes en su nombre, todos los ciudadanos pertenecen a una nación criminal. ¿Vamos a consentir que sea la nuestra?" 45 . La denuncia de Beauvoir se basa en la constatación de que, incluso por parte de antiguos miembros de la Resistencia, se utilizan métodos que apenas se distinguen de los de la ocupación, permitiendo prácticas propias del crimen político que contradicen sustancialmente los valores fundacionales de la nación francesa al desnaturalizar los ideales de libertad, igualdad y fraternidad. La acusación se extiende a la población de su país y, por tanto, a sí misma como miembro del pueblo francés, por la complicidad directa o indirecta con sus gobernantes, es decir, por una cola-

42 J, MURPHY, “Beauvoir and the Algerian War: Toward a Postcolonial Ethics”, cit., p. 279.

43 S. de BEAUVOIR, "Pro Djamila Boupacha", publicado como anexo en S. de BEAUVOIR y G. HALIMI, Djamila Boupacha. Proceso a la tortura, cit., pp. 226-229, p. 226.

$44 \quad$ Ibid., p. 228.

$45 \quad$ Ibid., p. 229. 
boración activa o pasiva con un régimen opresivo y violento, independientemente de las actividades y creencias políticas individuales.

En este breve artículo se concentran todos los argumentos que Simone de Beauvoir desarrolla desde el inicio de la guerra de Argelia en 1954 y que quedan reflejados de forma pormenorizada en el volumen de sus memorias titulado La force des choses ${ }^{46}$, publicado en 1963. Este libro autobiográfico recorre el periodo comprendido entre la liberación de París y la independencia de Argelia, y su segunda parte es en buena medida una narración retrospectiva del impacto que la situación argelina causó en su personalidad hasta llegar a redefinir su identidad. La experiencia cotidiana constata "la magnitud de la violencia que se manifestaba en la relación entre colonizadores y colonizados. Una relación estructuralmente violenta" ${ }^{47}$. A su juicio, las atrocidades y la tortura no eran un exceso o abuso sino la lógica propia de la guerra colonial que, "contra la voluntad colectiva e indomable" de "un pueblo resuelto a morir en masa antes que renunciar a su independencia", solo puede llevar a una conclusión: "el exterminio" ${ }^{48}$. En este sentido, como sostiene Sami Naïr: "El anticolonialismo de Beauvoir no se reduce a una cuestión de toma de conciencia política, se trata de una convicción filosófica profunda. La colonización supone a su juicio la dominación, a la vez violenta y opresiva, de un cuerpo sobre otro, de un Estado, de una sociedad y de una cultura sobre otras" ${ }^{49}$. En esta línea, resulta sorprendente comprobar la escasa atención que ha recibido este aspecto en la literatura dedicada a Simone de Beauvoir ${ }^{50}$, cuando resulta crucial para entender su evolución y las claves de su contribución a la filosofía política.

46 Nacida en 1908 en París, relató su infancia y adolescencia en Les Mémoires d'une jeune fille rangé (1958) y sus inicios como escritora, la guerra y la ocupación en La Force de l'âge (1960).

47 L. MARSO, "Simone de Beauvoir on Violence and Politics" en L. HENGEHOLD y N. BAUER (ed.), A Companion to Simone de Beauvoir, Wiley-Blackwell, Hoboken, 2017, pp. 299310 , p. 307.

48 S. de BEAUVOIR y G. HALIMI, Djamila Boupacha. Proceso a la tortura, cit., p.19.

49 S. NAÏR, Acompañando a Simone de Beauvoir. Mujeres, hombres, igualdad, Galaxia Gutenberg, Barcelona, 2019, p.103.

50 Julian Murphy, con apoyo en un gran número de referencias bibliográficas a las que remitimos, da cuenta de esta carencia especialmente en el caso de los críticos y biógrafos estadounidenses, que retratan a Simone de Beauvoir como una figura apolítica y literaria. Así, es recurrente la imagen de una escritora burguesa absorta por sus relaciones sentimentales y solo mínimamente involucrada en cuestiones políticas. No es raro encontrar una discusión mucho más amplia, por ejemplo, sobre su relación con el escritor Nelson Algren, que sobre su posición ante la guerra de Argelia. También es frecuente explicar las actividades políticas de Beauvoir en este terreno por la influencia de Sartre cuando en realidad hubo importantes dis- 
La guerra de Argelia marcó un punto de inflexión en su pensamiento, pero no supuso una ruptura respecto a las reflexiones y vivencias plasmadas en libros anteriores como Pour une morale de l'ambiguité o l'Amérique, le jour au jour, ambos publicadas en 1947. En el primero de ellos, que es uno de los pocos ensayos filosóficos sobre la ética desde una perspectiva existencialista, la libertad, condición primera de toda justificación de la existencia, es aquello que se quiere para sí mismo y también para los otros, lo que subraya la interdependencia entre todas las luchas de liberación y el rechazo de las diferentes formas de opresión. En su estancia en Estados Unidos, plasmada en el segundo de los libros citados, Beauvoir había descubierto la intersección entre raza y clase, y regresa impactada por la cuestión racial, que será desde entonces una de sus preocupaciones constantes. Las condiciones de vida de los negros y de los obreros obligan a denunciar conjuntamente el racismo y la explotación.

Durante el proceso argelino de liberación se agudiza el ataque de Simone de Beauvoir al racismo del patriota francés. Recordando el ambiente y los sucesos acaecidos en 1955, comenta que por aquel entonces la palabra independencia era tan impopular que nadie la pronunciaba y que incluso "en Les Temps Modernes, donde la deseábamos y la considerábamos inevitable, nos absteníamos de llamarla por su nombre", pues "el país entero, obreros y patrones, campesinos y burgueses, civiles y militares, cayó en el chauvinismo y en el racismo" ${ }^{51}$. Tras la humillación francesa en Indochina, la derecha no podía permitir que "los traidores clavaran el puñal por segunda vez en la espalda de la madre patria" 52 . Al mismo tiempo, "el partido comunista temía alejar a la masa al mostrarse menos nacionalista que los otros partidos" y "no combatía el racismo de los obreros franceses que veían a los 400.000 norteafricanos instalados en Francia a la vez como intrusos que les robaban

crepancias y una mayor implicación personal por parte de ella. En ocasiones, si se mencionan sus opiniones sobre Argelia, se describen como una obsesión casi patológica ligada al deseo de dar sentido a su vida. Como conclusión de este documentado estudio, podemos observar que los escritos de Beauvoir sobre Argelia apenas han merecido atención ni en los estudios sobre su obra ni tampoco en los análisis de la descolonización, y, además, suele omitirse la referencia a su libro en coautoría sobre Boupacha. En cambio, recuerda Murphy, como señaló Hélène de Beauvoir, al funeral de su hermana en 1986 acudieron muchas mujeres argelinas, junto a otras mujeres africanas. Véase el apartado titulado "Beauvoir and Her Critics" de J, MURPHY, "Beauvoir and the Algerian War: Toward a Postcolonial Ethics”, cit, pp. 276-279.

51 S. de BEAUVOIR, La fuerza de las cosas, cit., p. 400.

52 Ibid., p. 399. 
sus puestos y como un subproletariado despreciable" 53. Con la evolución de los acontecimientos bélicos, la prensa permanecía acrítica, habiéndose convertido "en una empresa de falsificación" y "el país consentía alegremente la guerra, con la condición de que se la disfrazase" ${ }^{54}$. Su malestar es evidente: "Soy una intelectual, concedo un valor a las palabras y a la verdad; tuve que soportar cada día, una y otra vez, la agresión de las mentiras que escupían todas las bocas" 55 .

A Beauvoir le duele la indiferencia de los franceses ante las atrocidades cometidas por su ejército en Argelia e incluso en la metrópoli bajo la dirección de Maurice Papon. Lo que resulta realmente deplorable y aterrador es que en un régimen democrático no se suscite una reacción contundente. En 1957 ya había muchas noticias que daban cuenta de "los huesos rotos, las quemaduras en la cara, en el sexo, las uñas arrancadas, los empalamientos, los gritos, las convulsiones [...] Batallones enteros saqueaban, incendiaban, violaban, masacraban. La tortura era empleada como medio normal y esencial de información. No se trataba de accidentes ni de excesos sino de un sistema" ${ }^{56}$. La coincidencia con Gisèle Halimi en el diagnóstico de la situación es evidente y también las quejas recurrentes sobre la apatía general: "Mis compatriotas no querían saber nada [...] La conspiración del silencio triunfó únicamente porque todo el mundo se hizo cómplice de ella" 57.

En medio de la exaltación patriótica y de la indiferencia generalizada, quienes denunciaron estos crímenes fueron considerados traidores de la patria. Los comentarios de Simone de Beauvoir al respecto muestran hasta qué punto la guerra de Argelia caló en su espíritu: "Me habían tratado, junto con otros, de antifrancesa: ahora lo era. No toleraba más a mis conciudadanos" ${ }^{58}$; "Me sentía tan desposeída como en los primeros tiempos de la ocupación. Y era aún peor, puesto que yo resultaba, lo quisiera o no, cómplice de esta gente entre la cual no soportaba ya estar. Es lo que menos les perdonaba. Hubiera

53 Ibid., p. 400.

54 Ibid., p. 430.

55 Ibid., p. 429. Años antes, con ocasión del juicio por colaboracionismo de Robert Brasillach, en el que Beauvoir se negó a firmar un escrito de petición de gracia (sería ejecutado en 1945), hace un comentario muy parecido citando a la filósofa Simone Weil: "Por oficio, por vocación, concedo una enorme importancia a las palabras. Simone Weil exigía que se condujera ante un tribunal a los que se sirven de la escritura para mentir a los hombres, y la comprendo. Hay palabras tan mortíferas como una cámara de gas", Ibid., p. 35.

$\begin{array}{ll}56 & \text { Ibid., p. } 431 . \\ 57 & \text { Ibid., p. } 432 . \\ 58 & \text { Ibid., p. } 433 .\end{array}$

ISSN: 1133-0937

DERECHOS Y LIBERTADES

DOI: https://doi.org/10.20318/dyl.2021.6102

Número 45, Época II, junio 2021, pp. 57-98 
sido necesario darme desde la niñez una formación de las SS, de paracaidista, en cambio de dotarme de una conciencia cristiana, democrática y humanista: sí, de una conciencia. Necesitaba mi propia estima para vivir, y me veía con los ojos de mujeres violadas veinte veces, de hombres con los huesos rotos, de niños enloquecidos: una francesa" ${ }^{59}$. La mirada del otro, lejos de objetivarnos y limitarnos, es para ella una condición de posibilidad de la propia constitución en sujeto moral. La responsabilidad aparece en la experiencia intersubjetiva, que es siempre una instancia crítica respecto al punto de vista en que nos situamos ${ }^{60}$. De este modo, Simone de Beauvoir se mira a sí misma desde la perspectiva de los argelinos y su posición dentro de la estructura colonial le resulta cada vez más inasumible. La dificultad proviene de este vínculo de pertenencia a un país del que se siente extraña, convirtiéndose esta sensación de extrañeidad en factor de concienciación política. No era desde luego la primera vez que se comprometía con la causa de los oprimidos, había colaborado en muchas iniciativas, había denunciado otras situaciones injustas, había escrito los ensayos ya citados y una novela política, Les Mandarins, con la que gana el premio Goncourt, además de fundar una revista tan reivindicativa como Les Temps Modernes. Pero nunca se había sentido ajena a su ciudadanía francesa ni había vivido esta condición de un modo tan trágico: "Yo ya no soportaba esta hipocresía, esta indiferencia, este país, mi propia piel. Esa gente en la calle, cómplice o aturdida, eran los verdugos de los árabes: todos culpables. Y yo también. 'Soy francesa'. Estas palabras me desgarraban la garganta, como la confesión de una tara [...] Me parecía arrastrar una de esas enfermedades cuyo síntoma más grave es la ausencia de dolor" ${ }^{61}$.

$59 \quad$ Ibid., p. 434.

60 El problema de la alteridad y la responsabilidad es abordado tempranamente por Simone de Beauvoir y marca importantes diferencias con Sartre, al tiempo que da cuenta de su influencia mutua. Como recuerda Verónica González, ya en dos de sus primeros escritos, Pyrrhus et Cinéas (1944) y La sang des autres (1945) cita la misma frase de Dostoievski: "Cada hombre es responsable de todo, ante todos", y en Pour une morale de l'ambiguité (1947) subraya que el existencialismo no es un solipsismo. Siguiendo a Michel Kail, a diferencia de los planteamientos sartreanos expuestos en L'Être et le Néant (1943), el hecho de que Beauvoir integrara el problema del otro en sus análisis en torno a la subjetividad influyó en los desarrollos de Sartre en la Critique de la raison dialectique (1960) Véase V. GONZÁLEZ, "'Mis lágrimas deciden'. Sobre alteridad/es en Simone de Beauvoir" y M. KAIL “Beauvoir y Sartre, la puesta en juego de la alteridad" en O. GRAU et al. (ed.), Simone de Beauvoir en sus desvelos. Lecturas feministas, Centro de Estudios de Género, Universidad de Chile, 2016, pp. 253-271 y 273-294.

61 S. de BEAUVOIR, La fuerza de las cosas, cit, p. 451. Según Annabelle Golay, la vergüenza se revela entonces como un sentimiento fundamental, que sostiene su gesto de escritura, frente a frente consigo misma bajo la mirada del otro; decir su vergüenza, escribirla, consti- 
La guerra de Argelia tuvo un impacto tan decisivo en Simone de Beauvoir que, según afirma, llegó a invadir su pensamiento, su sueño, su estado de ánimo. En el epílogo de La fuerza de las cosas, cuando Simone de Beauvoir hace un balance de sus experiencias, la naturaleza trágica de la guerra y de su propia posición vuelve a ponerse de manifiesto. Con amarga sinceridad, reconoce que su fama y sus privilegios son parte del poder colonial francés y de un sistema económico que ella detesta, pero del que se beneficia: "Sé que soy una aprovechadora y ante todo por la cultura que he recibido y las posibilidades que me ha proporcionado. No exploto directamente a nadie; pero toda la gente que compra mis libros es la beneficiaria de una economía fundada en la explotación. Soy cómplice de los privilegiados y estoy comprometida con ellos: por esto he vivido la guerra de Argelia como un drama personal. Cuando se está en un mundo injusto es inútil esperar purificarse por algún procedimiento; lo que habría que hacer es cambiar el mundo y eso no está en mi poder. Sufrir sus contradicciones no sirve de nada; olvidarlas es mentirse" 62. Este callejón sin salida le lleva a sentirse muy alejada de un optimismo de lo absoluto capaz de tranquilizar la conciencia, sintiéndose, en cierto sentido, engañada. La experiencia de la vida, la realidad existencial, sobre todo a partir de la guerra de Argelia, le había mostrado el dolor, el hambre, la desesperación de millones de personas que viven la desdicha desnuda y ni siquiera pueden explicar sus sufrimientos. El escándalo es lo impronunciable y lo irrecuperable del mal ${ }^{63}$. Se trata de situaciones que "ignoraba cuando era joven y cuando imaginaba que descubrir el mundo significaba descubrir algo hermoso": "En ese aspecto también he sido engañada por la cultura burguesa y a eso se debe el que no quiera contribuir a engañar a los demás. En síntesis, cuando digo que he sido engañada lo hago para que los otros no sean engañados. En realidad, también es un problema de tipo social" ${ }^{64}$. Por eso se siente con la obligación de alertar a los demás de la necesidad de experimentar la verdad de la condición humana sin mentirse, pues lo único absoluto es lo absoluto de la desdicha ${ }^{65}$.

tuye el punto de partida para una moral solidaria y de la relación con los demás. A. GOLAY, "Féminisme et postcolonialisme: Beauvoir, Fanon et la guerre d'Algérie", International Journal of Francophone Studies, vol 10 núm. 3, 2007, pp. 407-424, p. 418.

62 S. de BEAUVOIR, La fuerza de las cosas, cit., p. 756.

63 Ibid., p. 757.

64 Entrevista con Madeleine Gobeil en S. de BEAUVOIR. Entrevistas, trad. L. Sánchez y M. Hincapié, ennegativo ediciones, Medellín, 2019, pp. 21-33, p. 32.

65 S. de BEAUVOIR, La fuerza de las cosas, cit., p. 758. 
La izquierda francesa se había mostrado dividida y errática respecto a la guerra de Argelia, no había mantenido una posición coherente contra el colonialismo francés, y era incapaz de dar voz a quienes sufrían de forma tan extrema la injusticia y el dolor. En 1955 Beauvoir todavía creía posible "hacer algo por la independencia por medios legales" ${ }^{66}$, pero, conforme avanzan los acontecimientos, la aproximación a las actividades del FLN, a la red de apoyo dirigida clandestinamente por Francis Jeanson, la firma del Manifiesto de los 121 apelando a la insumisión ${ }^{67}$ y las críticas a Albert Camus y a todos aquellos que se oponían frontalmente al uso de la violencia como respuesta a la violencia, eran la prueba de la radicalización de su posicionamiento público $^{68}$. Con la intención reiterada de no engañarse ni engañar a los demás, concluye: "Ya que la izquierda no había logrado llevar a cabo un combate eficaz dentro de la legalidad, si uno quería permanecer fiel a las convicciones anticolonialistas y romper toda complicidad con esta guerra, no quedaba otra posibilidad que la acción clandestina. Yo admiraba a aquellos que se dedicaban a ella, pero exigía un compromiso total, y pretenderme capaz de él hubiese sido hacer trampa: no soy mujer de acción; la razón de mi vida es escribir, para sacrificarla, hubiese tenido que sentirme indispensable en otro lado, y no era para nada el caso. Me conformé con hacer favores cuando me los pedían; algunos de mis amigos hicieron más que yo" ${ }^{69}$.

\subsection{Responsabilidad compartida}

Uno de estos favores fue su respuesta a la llamada de Gisèle Halimi para defender la causa de Djamila Boupacha, cuya primera manifestación sería el referido artículo de Le Monde de 2 de junio de 1960, y que alcanzaría su máxima expresión a través del libro Djamila Boupacha, publicado en 1962 y editado en castellano solo dos años después con el elocuente subtítulo Proceso a la tortura. Como sugiere Judith Surkis, sus dos intervenciones escritas sobre

66 Ibid., p. 435. Más tarde, en otro libro autobiográfico, All Said and Done (Warner Books, New York, 1974, p. 125) constatará con decepción que “en octubre de 1963 las torturas y las masacres ya eran historia antigua, que no preocupaba a nadie".

67 Así llamado por el número de firmantes, aunque su nombre es "Declaración sobre el derecho a la insumisión en la guerra de Argelia". El Manifiesto fue censurado y hubo incriminaciones por apología de la insumisión y de la deserción e incitación a la desobediencia.

68 Gisèle Halimi manifiesta una clara oposición a toda justificación del uso de la violencia y, como adepta de la no-violencia, se distancia de Sartre. Véase G. HALIMI, La lait de l'oranger, cit., p. 376.

69 S. de BEAUVOIR, La fuerza de las cosas, cit., pp. 537-538. 
este asunto, una al comienzo y otra al final, fueron cuidadosamente ubicadas $^{70}$. Simone de Beauvoir fue quien propuso en julio de 1961 que se redactase un libro o un folleto con una relación completa del caso ${ }^{71}$. A través de esta iniciativa y de la aceptación de la coautoría del libro de Gisèle Halimi, realiza un gesto muy comprometido, que le reportaría graves consecuencias en forma de desprestigio, insultos y amenazas ${ }^{72}$, y sobre todo un gesto muy excepcional, ya que nunca había firmado un libro con otra persona, ni siquiera con Sartre a pesar de su simbiosis intelectual ${ }^{73}$. La autora recuerda en sus memorias que aceptó suscribir el texto escrito por Gisèle Halimi "para compartir la responsabilidad" 74 , con plena conciencia del alto precio que las dos deberían pagar por continuar en el empeño de dar la máxima visibilidad pública al caso $^{75}$.

Simone de Beauvoir, además de aparecer formalmente como coautora del libro -aunque al inicio del cuerpo de la redacción consta solo el nombre de Gisèle Halimi- escribe el prólogo, que, por su estilo literario, resulta también excepcional en el marco global de su obra, compuesta de ensayos, novelas y escritos autobiográficos. El prólogo no pertenece a ninguno de estos registros, aunque sí mantiene el tono personal y directo de sus memorias, que en la segunda parte de La fuerza de las cosas, tal como hemos visto, se materializa en el relato de una vivencia íntima y descarnada de la guerra de Argelia. La novedad reside ante todo en su fuerte carácter interpelante; es una exhortación dirigida a la opinión pública para que tome partido a fa-

70 J. SURKIS, "Ethics and Violence. Simone de Beauvoir, Djamila Boupacha and the Algerian War", French Politics, Culture E Society, vol. 28, núm. 2, 2010, pp. 38-55, p.45.

71 La propuesta sería aprobada por unanimidad. Y el libro quedó "abierto" y fue completado por toda una serie de testimonios y documentos.

72 Según Melissa Ptacek, de todas las incursiones públicas en relación con la denuncia de la tortura en la guerra de Argelia, la que más avivó la ira de sus oponentes, incluso con amenazas de muerte, fue la intervención en el caso de Djamila, M. PTACEK, "Simone de Beauvoir's Algerian war: torture and the rejection of ethics", Theory and Society, núm. 44, 2015, pp. 499-535, p. 522.

73 En un momento de La fuerza de las cosas, Simone de Beauvoir escribe: "Nuestros pensamientos se han criticado, corregido, sostenido, con tanta asiduidad, que nos son totalmente comunes", cit., p. 746 .

$74 \quad$ Ibid., p. 712.

75 Según Anne Strasser, con este prólogo, el año de la publicación del libro, 1962, marca el compromiso de Beauvoir sola; un compromiso que pasa ante todo por su pluma pero que le obligará a lanzarse a la batalla y salir a la calle, A. STRASSER, "1962: Simone de Beauvoir ou le désenchantement" en P.L. FORT y Ch. ACHOUR (ed.), La France et l'Algérie en 1962, Karthala, Paris, 2013, pp.149-161, p.156. 
vor de una mujer torturada y en contra de un gobierno que practica y tolera la tortura. Las palabras adquieren el valor de un requerimiento "en un movimiento -subraya Diane Perpich- que es retóricamente poderoso pero inusual en ella" ${ }^{76}$, pues le plantea directamente al lector la elección entre la siguiente alternativa: "O se coloca de parte de los verdugos de quienes sufren hoy y consiente tranquilamente el martirio al que, en nombre de usted, y casi ante sus ojos, son sometidos millares de Djamilas y de Ahmeds; o bien rechaza usted no sólo ciertos procedimientos, sino también el fin que los autoriza o los reclama [...] No hay terceros caminos" 77 .

Claude Francis y Fernande Gontier, tras invocar los inicios del prólogo -en que se califica la represión de genocidio por haber causado más de un millón de víctimas y haber convertido los centros de reagrupamiento en campos de exterminio, sirviendo accesoriamente de burdeles a los cuerpos de élite-, señalan que nos encontramos ante "uno de los temas más importantes del pensamiento de Simone de Beauvoir: el desvelamiento" y que ya “desde 1945, en España y en Portugal, se había tropezado con la incredulidad de su auditorio cuando había descrito la ocupación y los campos de concentración" 78. En este sentido, el libro "es interesante sobre todo porque desmonta, pieza por pieza, una máquina de mentiras tan perfectamente construida que, durante los últimos siete años, apenas si ha permitido que se filtrasen algunos vislumbres de verdad. ¡Cuántas veces he chocado contra esta respuesta: 'de todos modos, si fuese una cosa tan corriente, tan enorme, tan horrible, se sabría'! Pero precisamente porque es tan corriente, tan horrible y tan enorme, era necesario que no se supiera". De este modo, "lo excepcional en el caso Boupacha no son los hechos: lo excepcional es que hayan sido puestos al descubierto" 79 .

A este propósito, con el objetivo directo de la suspensión del juicio en Argel, previsto para el 17 de junio, y del traslado de la acusada y de la causa a Francia, Gisèle Halimi y Simone de Beauvoir crearon el Comité pour Djamila Boupacha, cuya actividad trataría de convertir a la militante "en un símbolo", con el objetivo final de lograr el castigo, efectivo y público, de sus torturado-

76 D. PERPICH, "Beauvoir's Legacy to the Quartiers: The Changing Face of French Feminism," en L. HENGEHOLD y N. BAUER (ed.), A Companion to Simone de Beauvoir, cit., pp. 489-499, p. 496.

77 S. de BEAUVOIR y G. HALIMI, Djamila Boupacha. Proceso a la tortura, cit., p. 20.

78 Cl. FRANCIS, F. GONTIER, Les écrits de Simone de Beauvoir. La vie, l'écriture, avec en appendice textes inédites ou retrouvés, Gallimard, Paris, 1979, p. 201.

79 S. de BEAUVOIR y G. HALIMI, Djamila Boupacha. Proceso a la tortura, cit., p. 10. 
res $^{80}$. Françoise Sagan escribió un artículo a su favor en L'Express justamente un día antes de la fecha señalada para el juicio. Y de nuevo se conseguiría el aplazamiento, ya que, tras otra visita a la cárcel de Barberousse, Halimi fue expulsada del país dos días antes de la vista y "el tribunal, que conocía las reacciones que el asunto había provocado, no se había atrevido a juzgar a la joven en ausencia de su abogada" ${ }^{81}$. La indignación ante estos hechos hizo que el comité fuera sumando a "personalidades adheridas a las corrientes políticas, filosóficas y religiosas más diversas" ${ }^{82}$, algunas de las cuales colaboraron en la parte del libro dedicada a los "testimonios". Hay que destacar que se contó también con el singular apoyo de Pablo Picasso, que en diciembre de 1961 hizo un bello retrato de Djamila Boupacha con el que se ilustró la cubierta del libro. La historia de la activista torturada inspiró ese mismo año al pintor Roberto Matta para Le Supplice de Djamila y en 1962 al músico Luigi Nono ${ }^{83}$.

Los miembros del comité que tuvieron un papel más activo fueron Anise Postel-Vinay y Germaine Tillion, representantes eminentes de la resistencia y de la deportación, la escritora Bianca Lamblin, que figuraría como secretaria, y por supuesto Gisèle Halimi y Simone de Beauvoir, que ostentará el cargo de presidenta. A pesar de tratarse de un comité mixto, con una importante presencia masculina, el evidente protagonismo de las mujeres en las acciones en defensa de Djamila Boupacha ha llevado a profundizar en la dimensión de género de este movimiento pues fue, sin duda, un paso importante hacia la visibilidad de las mujeres en la acción política. Vanessa Codaccioni reflexiona sobre este aspecto, destacando que la especificidad de la aportación de las intelectuales que colaboraron en el comité reside en un activismo particularmente comprometido, que "a la inversa de sus homólogos varones, no se reduce a un simple posicionamiento" ${ }^{84}$. La impronta que

$80 \quad$ Ibid., p. 75.

81 S. de BEAUVOIR, La fuerza de las cosas, cit., p. 585.

82 Entre las adhesiones al comité, encontramos las firmas de Jean Amrouche, Aimé Cesaire, Lucie Faure, Edouard Glissant, René Julliard, Helène Parmelin, Jean-Paul Sartre, Elsa Triolet, André Schwarz-Bart, Gabriel Marcel, Jacques Lacan o Maurice Merleau-Ponty.

83 En pintura, el libro incluye también una serie de "estudios para un homenaje a Djamila Boupacha" de Robert Lapoujade; Roberto Matta pintó otro cuadro de denuncia de la tortura en Argelia titulado La question, y Picasso Les femmes d'Alger. En el cine, Caroline Huppert dirigió Pour Djamila (2012). Asimismo, varias obras literarias se han inspirado en su figura, como la novela Dâ (Soureyeh Mehr Téhéran, 2008, p. 11) de la escritora kurda iraní, Azam Hosseini.

84 V. CODACCIONI, "(Dé)Politisation du genre et des questions sexuelles dans un procès politique en contexte colonial: le viol, le procès et l'affaire", cit., p. 39. 
dejaron en el comité se manifestó ante todo en una primera toma de conciencia de la relevancia política que podían tener las prácticas de solidaridad entre mujeres. Esta concienciación, ligada a la denuncia de violación, marca una importante diferencia con el affaire Djamila Bouhired en el que, como observa Maya Boutaghou, también se puso de relieve la lucha de las mujeres por la independencia de Argelia y la fuerte implicación de algunos intelectuales. La creación de una red de apoyo resultó imprescindible para la movilización política ${ }^{85}$.

Gisèle Halimi, al recordar el inicio de su trabajo en el caso Boupacha, se refiere a la toma de conciencia de ese crucial "descubrimiento del movimiento de las mujeres -hecho personal igual a hecho politico- que explica la condición de cada una por la condición de todas. Y a la inversa". La consecuencia es un "enfoque global", que incluye "análisis y combate" y que está "necesariamente precedido por la escucha de los datos de una vida. Sin olvidar su afectividad y sus aspectos psicológicos. La sororidad lo exige, el cambio también" ${ }^{86}$. Por su parte, Simone de Beauvoir, aunque "había aceptado la responsabilidad y la presidencia del comité", parecía rechazar "cualquier aproximación sensible al problema. Ella consideraba a Djamila como una víctima entre miles, un 'caso' útil para llevar a cabo la batalla contra la tortura y la guerra". Gisèle Halimi contrasta esa posición un tanto abstracta con su propia actitud ya que, nos dice, "yo deseaba restituir un poco de humanidad al enfrentamiento político, dar vida a Djamila ante la opinión pública como la había visto en la prisión. Una joven musulmana violada por los paracaidistas, quemada, destrozada, que seguía traumatizada por su estancia en el mundo de la barbarie y por la amenaza de una condena a muerte" 87.

Este contraste se pone de manifiesto en la primera conferencia de prensa del comité, el 24 de junio de 1960. El acto, cubierto por numerosos periodistas franceses y extranjeros, fue presidido por Simone de Beauvoir junto a Germaine Tillion, cuya presencia resultaba especialmente relevante por su condición de reputada etnóloga experta en la historia de Argelia. Tras darse a conocer los hechos, Bianca Lamblin lee una carta del padre de Djamila, también torturado, que describe los diferentes suplicios sufridos y habla de su

85 M. BOUTAGHOU, "Trois puissantes femmes: Simone de Beauvoir, Gisèle Halimi, Djamila Boupacha, Entre lutte anticoloniale et combat féministe", Dalhousie French Studies, núm. 103, 2014, pp. 9-21, p. 9.

86 G. HALIMI, La lait de l'oranger, cit., p. 348.

87 Ibid., p. 352. 
dolor, de sus gritos, de sus protestas ${ }^{88}$. La secretaria del comité hace esfuerzos para que no se le quiebre la voz, pero finalmente se rompe en sollozos. En ese momento, recuerda Halimi: "Simone de Beauvoir le arranca la hoja de las manos. Bruscamente. Y continúa ella misma la lectura. Contrariada por este fallo y como para evitar toda emoción, adopta un tono lo más seco posible y termina el relato". Al final de la reunión, se queja: "Es ridículo... ¿ por qué Bianca se ha puesto a llorar?" 89 . En otros pasajes de La lait de l'oranger, Halimi también lamenta que Simone de Beauvoir nunca tuviera especial interés en conocer personalmente a Djamila y que, en general, siempre se pusiera una coraza cuando la emoción arriesgaba por aflorar, como "para conjurar una debilidad culpable, una carencia en la lucha, un error de comportamiento". Sin embargo, añade: "Ello no impidió que en cada ocasión -Tribunal Russell contra los crímenes de guerra en Vietnam, dictadura de los coroneles griegos, batallas feministas- me mantuviera intacta en mi fervor por ella, y a su lado" ${ }^{90}$. Las dos firmarían el Manifiesto de las 343 por la despenalización del aborto, fundarían el movimiento Choisir la cause des femmes y participarían en muchas otras actividades feministas.

Sin evitar los desacuerdos a lo largo de este camino recorrido conjuntamente en los años setenta, el inicio estuvo jalonado por el asunto Boupacha y el trabajo en el seno del comité, que supuso realmente un despertar a la acción práctica como proyección del análisis teórico. El comité fue el banco de pruebas de una posible convergencia entre mujeres de diferentes corrientes ideológicas y discrepantes en muchos aspectos ${ }^{91}$ a la hora de luchar por los propios derechos, apuntando a una transversalidad, reclamada posteriormente, pero que nacía ahora de la necesidad acuciante de defender la dignidad pisoteada de otra mujer y de tratar de reparar de algún modo la injusticia causada por un dolor en sí mismo irreparable.

El paso siguiente para salvar a Djalima y perseguir a los torturadores sería conseguir la recusación o el desistimiento de los tribunales de Argel y sólo el ministro de Justicia, Edmond Michelet, estaba habilitado para solici-

88 S. de BEAUVOIR y G. HALIMI, Djamila Boupacha. Proceso a la tortura, cit., p. 104.

89 G. HALIMI, La lait de l'oranger, cit., p. 353.

$90 \quad$ Ibid., pp. 357-358.

91 De hecho, la propia Germaine Tillion, que, como etnóloga primero y como observadora después, había pasado largos periodos en Argelia desde 1935, escribirá una carta abierta a Simone de Beauvoir en 1964 donde señala que, gracias a este conocimiento directo de la situación, rechaza la violencia provenga de donde provenga y se siente unida al dolor de las víctimas por encima de las opciones políticas. 
tarlo ante la Corte de Casación. No se podía perder tiempo, y al día siguiente de la conferencia de prensa se entrevistaría con él una delegación del comité compuesta por Simone de Beauvoir, Gisèle Halimi, Germain Tillion y Anise Postel-Vinay. En La lait de l'oranger se resalta el papel jugado por las dos últimas ya que, "al oponerse en este punto al gobierno que ellas habían elegido, gaullista como ellas, atrajeron a una parte de la opinión fluctuante -o incluso indiferente- ante los acontecimientos de Argelia. Por la vía del patriotismo moral" 92. Simone de Beauvoir explica en sus memorias esta visita y el malestar que le produjo un responsable político que, reconociendo la existencia de la tortura y calificándola de gangrena, parecía incapaz de tomar una decisión. De hecho, él mismo se remitió a lo que le aconsejara el presidente de la Comisión de Salvaguardia de los Derechos y las Libertades Individuales (presidente también de la Sala de lo penal del Tribunal de Casación y miembro del Consejo Constitucional), Maurice Patin, magistrado al que consideraba "una conciencia" 93 .

Así, a petición del ministro Michelet, la delegación del comité consiguió reunirse esa misma tarde con Patin. La narración de este encuentro es una de las páginas más sórdidas del asunto Boupacha y podríamos decir que de la historia de la tortura, tanto que Simone de Beauvoir dice verse obligada a volver sobre ella a pesar de aparecer con todo detalle en el libro firmado en coautoría. Según Diane Perpich, la semblanza del presidente de la Comisión en La fuerza de las cosas es una representación mordaz de la indiferencia moral burocrática, si bien la escritura se mantiene en un nivel descriptivo sin pasar a un análisis de algo similar a la banalidad del mal de Hannah Arendt ${ }^{94}$. El encuentro comenzó de un modo natural, Germaine Tillion fue la primera en tomar la palabra justificando la petición de inhibición del tribunal de Argel en el hecho de haber visto muchos casos de tortura y, sin embargo, ni una sola querella que acabara en sanción. Entonces Maurice Patin extendió la mano hacia una pila de documentos: "violaciones, muertes, torturas, todo estaba escrito allí, lo admitía y parecía preguntar: ¿qué puedo hacer?" 95 El orden en Argel solo podía reinar gracias a la acción de los militares, y a él "nadie le comprendía, su papel era difícil y su tarea abrumadora" ${ }^{96}$. Además,

92 G. HALIMI, La lait de l'oranger, cit., p. 399.

93 S. de BEAUVOIR, La fuerza de las cosas, cit., p. 586.

94 D. PERPICH, "Beauvoir's Legacy to the Quartiers: The Changing Face of French Feminism", cit., p. 496.

95 S. de BEAUVOIR, La fuerza de las cosas, cit., p. 587.

96 S. de BEAUVOIR y G. HALIMI, Djamila Boupacha. Proceso a la tortura, cit., p. 110. 
su reacción fue ya de entrada muy mezquina pues responsabilizó de esos "excesos" -no admitía hablar de tortura- a la escoria de los soldados novatos que se quedan con los detenidos por la noche cuando no están bajo la vigilancia de los oficiales. De repente, dirigiéndose a Simone de Beauvoir, le reprochó no haber contado los hechos con exactitud, haber cometido un delito por publicar la querella y haber dado con su artículo un gran disgusto a los militares "que son verdaderos señores" 97 y muy gentiles. Halimi no quería desviarse del asunto y le explicó que Djamila había estado en manos de los torturadores treinta y tres días, que había sido maltratada. De repente, Patin la interrumpió: “¡Ah! Sí, ¡la botella!... cuénteme eso... ¿cómo le dijo su cliente que se la habían metido?". Halimi repitió el relato de Djamila. "Ella estaba atada, boca arriba..." El rostro de M. Patin se iluminó: “¡Ah bueno!... ¡Entonces no se trata del verdadero suplicio!... como en Indochina, ¿no lo saben ustedes? (...) En Indochina se hacía de la siguiente manera: se sentaba al individuo encima de la botella... es muy violento... los intestinos revientan..., por otra parte, en general se mueren". Esto último lo dijo "con una amable sonrisa" ${ }^{98}$. Y de pronto, otro añadido igualmente impúdico: “Ustedes pretenden que ella era virgen. Pero, en fin, tenemos fotos de ella tomadas en su cuarto: está entre dos soldados de la ALN, con las armas en la mano y tiene una ametralladora" 99 . Y otra observación, “¡esa Djamila no es nada simpática!”, seguida del argumento decisivo: “¡no quieren a Francia!”; a lo que Simone de Beauvoir respondió: "Con lo que han visto de Francia y de las botellas que les meten en el vientre a las chicas, no es extraño que no la quieran" ${ }^{100}$. Cuando Germaine Tillion se levantó dando por terminada una conversación que, como aquella de hace años entre Gisèle Halimi y el general Massu, no tenía salida posible, el presidente de la Comisión aún hizo alguna consideración más "sobre la psicología de Djamila": "¡se cree una Juana de Arco!", a lo que Anise Postel-Vinay replicó desde el umbral de la puerta: "En 1940, cuando teníamos veinte años éramos muchas las que nos creíamos Juana de Arco" ${ }^{101}$. Patin acabó por estallar "sacando las uñas: No es lo mismo señora, usted, usted es francesa" ${ }^{\prime 102}$.
$97 \quad$ Ibid., p. 108.
98 Ibid., p. 109.
99 S. de BEAUVOIR, La fuerza de las cosas, cit., p. 588.
100 S. de BEAUVOIR y G. HALIMI, Djamila Boupacha. Proceso a la tortura, cit., p. 111.
101 S. de BEAUVOIR, La fuerza de las cosas, cit., p. 589.
102 S. de BEAUVOIR y G. HALIMI, Djamila Boupacha. Proceso a la tortura, cit., p. 111. 


\section{LA DENUNCIA DE LA VIOLENCIA SEXUAL, PRIMER PASO HACIA UNA JUSTICIA DE GÉNERO}

\subsection{Un proceso que se cierra}

Esta entrevista, citada in extenso sin omitir los detalles pues todo ellos son reveladores, es una experiencia directa de los elementos que rodearon la práctica de la tortura en la dominación colonial francesa y que, siguiendo a Ryan Kunkle $^{103}$, podrían sintetizarse en dos niveles de jerarquía, ligados ambos a la raza: la jerarquía de clase, pues incluso dentro del propio ejército se marca una clara diferencia por el estatus social entre la "escoria" local y la élite de los europeos, y la jerarquía de género, pues la violación no se considera auténtica tortura, se culpabiliza a la víctima por su comportamiento anterior y se niega todo posible rasgo de heroicidad en una mujer argelina. En el fondo, de forma velada, todo está justificado por el mantenimiento del orden público en un país sometido, $\mathrm{y}$, precisamente, nada cuestiona más los códigos culturales de ese orden y de esa sumisión que la actitud de una mujer musulmana cuyo cuerpo torturado todavía es capaz de sustentar la rebelión.

La tenacidad de Djamila Boupacha a la hora de resistir a las presiones queda patente en su negativa a aceptar el acuerdo que se le propuso para intentar zanjar el asunto: "un psiquiatra la declararía irresponsable; sería absuelta, pero, al mismo tiempo, sus revelaciones perderían todo crédito; el proceso que pensaba iniciar contra sus torturadores no tendría lugar" 104 . Gracias a esta determinación, el caso continuaba abierto, pero nadie parecía atender a la demanda de traslado a Francia. En medio del impasse, aparece en escena una figura que, en caso de actuar, pues no hay certeza sobre quién dio la orden ${ }^{105}$, lo hizo con tanta eficacia como discreción: Simone Veil, la por entonces magistrada destacada en el ministerio de Justicia que sería unos años después ministra de Sanidad y presidenta del Parlamento Europeo. Anise Postel-Vinay y Germaine Tillion, compañeras de deportación, recurrieron a ella y, a los pocos días, ya en el mes de julio, en un Dakota militar, Djamila aterriza en Villacoublay camino a las prisiones de Fresnes, Pau, Lisieux y Rennes.

103 Véase R. KUNKLE, “’We Must Shout the Truth to the Rooftops': Gisèle Halimi, Djamila Boupacha, and Sexual Politics in the Algerian War of Independence", Iowa Historical Review, vol. 4 núm. 1, 2013, pp. 5-24.

104 S. de BEAUVOIR y G. HALIMI, Djamila Boupacha. Proceso a la tortura, cit., p. 13.

105 Véase, G. HALIMI, La lait de l'oranger, cit., pp. 398-399. 
Lo importante ahora era el reconocimiento médico para un examen ginecológico, que determinara si la violación causó la pérdida de la virginidad, y un examen psicológico, que evaluara el choque emocional padecido. Con la dificultad de ponerse de acuerdo los cinco médicos que la reconocieron, se determinó que, aunque habían pasado demasiados meses para poder precisar la modalidad de la desfloración, los signos parecían avalar que se produjo de forma traumática. En cuanto al examen pericial psicosomático, en la parte redactada por la doctora Hélène Michel-Wolfrom ${ }^{106}$, se estableció que su mentalidad era la de una virgen, que era incapaz de simulación o de mentira y que sufría "una neurosis de angustia, postraumática, con rasgos fóbicos y preocupaciones obsesivas" ${ }^{107}$. Gisèle Halimi subraya la satisfacción de Simone de Beauvoir ante las conclusiones de este informe médico que presentó el 1 de diciembre de 1960 en una reunión del comité.

Dos semanas después, por decreto del 15 de diciembre ${ }^{108}$, por fin el Tribunal de Casación confirma la inhibición definitiva del tribunal de Argel en favor del de Caen. Era un paso decisivo, aunque todavía quedaba un largo camino por recorrer. En junio de 1961, primera comparecencia de Djamila ante el tribunal y primer encuentro en Francia con sus padres tras un año sin verlos. En ese mismo mes, comisión rogatoria del juez Chausserie-Laprée, -un juez inquebrantable e impermeable a todas las presiones- solicitando de las autoridades de Argel las fotografías de todos los militares y policías que habían estado cerca de Djamila. Aún faltaban varios meses de espera y de sufrimiento en la cárcel de Lisieux para que Djamila Boupacha, que se había sumado a la huelga de hambre de los argelinos y argelinas detenidos en Francia, fuera conducida en una camilla ante el tribunal para mantener un careo con el doctor de El Biar y reconocer a sus torturadores en el test de las fotografías. Además, se contó con una pieza central, la declaración de Zineb Larousse, única testigo de las torturas sufridas por Djamila en Hussein Dey. En Argel esta presa lo había negado todo, pero otras dos argelinas detenidas

106 Autora de Los conflictos sexuales de la mujer, trad. de A. Garzón, Extemporáneos, México, 1973.

107 Sobre los elementos constitutivos y específicos del trauma de la tortura, véase M. LALATTA COSTERBOSA, “Argumentos contra la tortura. La definición de tortura, el Estado de Derecho y el Tribunal Europeo de Derechos Humanos", Derechos y Libertades, núm. 39, 2018, pp. 17-33.

108 El día anterior, la Asamblea General de las Naciones Unidas aprueba la Resolución 1514 sobre la independencia de los pueblos coloniales, que los argelinos consideran todavía hoy como un texto escrito con la sangre de sus mártires. 
habían escrito al ministro de Justicia pidiendo que las careasen con ella pues "creían poderle hacer decir la historia de Djamila tal como se la había confiado a ellas un día de verdad o un día de debilidad" ${ }^{109}$. Y, en efecto, ante el tribunal de Caen, en noviembre de 1961, la testigo Zineb Laroussi "confiesa haber mentido siempre ante los jueces de Argel: Sí, Djamila fue torturada. Atrozmente. Ella vio incluso sus bragas manchadas de sangre después del suplicio de la botella. Y hasta la veló, mientras estaba desmayada" ${ }^{110}$.

En este mes de noviembre, en una conferencia de prensa del comité, Simone de Beauvoir, apoyada por los profesores Pierre Cot, André Hauriou, Maurice Duverger y Charles-André Julien, anunció que Djamila Boupacha iba a interponer una querella con constitución de parte civil contra el general Charles Ailleret y el ministro Pierre Messmer, por tratar de impedir que los torturadores de Djamila fueran identificados oficialmente. Se les acusaba de encubrimiento de malhechores (art. 61 del Código penal) y de crimen de ataque a las libertades públicas y a la Constitución -separación de poderesprevisto por el artículo 114. Tanto la abogada como el resto del comité eran conscientes de que no se conseguiría que fueran condenados, pero podrían salir a la luz pública sus responsabilidades. Sin embargo, ni siquiera eso fue posible ya que una orden de incompetencia dictaminó que la Constitución de 1958 no permitía llevar a un ministro ante la jurisdicción de derecho común y, además, días después de interponer apelación, el 18 de marzo se firmarían los Acuerdos de Evian entre una delegación del FLN y otra del Gobierno francés. Era el primer acto del nacimiento de la Argelia independiente, en el que se decretaría la liberación de todos los prisioneros en poder de las dos partes a la entrada en vigor del alto el fuego.

Al tratarse de una amnistía general, la impunidad resultó inevitable, lo que refuerza la exigencia de un trabajo de memoria realizado por los testigos de aquellos acontecimientos, más allá de la historia oficial que solo muy tardíamente ha comenzado a reconocer los crímenes políticos cometidos y la práctica extendida de la tortura. En este sentido, siguiendo a Fabiana Grasselli, el asunto Boupacha, en el relato testimonial de Halimi y Beauvoir, tiene efectos políticos e incluso performativos, ya que, como sugiere Elisabeth Jelin, la elaboración de una memoria narrativa de la represión experimentada en el propio cuerpo es necesariamente pública en la medida en

109 S. de BEAUVOIR y G. HALIMI, Djamila Boupacha. Proceso a la tortura, cit., p.151.

110 Ibid., p. 190. 
que es compartida y comunicada ${ }^{111}$. El testigo habla por todos aquellos que no pueden hacerlo, silenciados o desaparecidos: "No soy más que una detenida entre millares" ${ }^{\prime 12}$.

Como consecuencia de los Acuerdos, el 21 de abril Djamila Boupacha sale de la cárcel en cuya puerta espera Gisèle Halimi, quien la acogería en su casa hasta su vuelta forzada a Argel el día 8 de mayo. La joven quería permanecer en París para ampliar sus estudios, pero enseguida empezaron las llamadas para pedirle que regresara a Argelia con sus hermanos y hermanas liberados. Todo se sucede muy rápidamente, ya que la organización protestante, La Cimade, propone un encuentro para conocer su historia, y, al traspasar la puerta del local, se pierde su pista. Gisèle Halimi no vuelve a verla hasta varios meses más tarde en Argel, ya casada y empleada en el ministerio de Asuntos sociales y de Trabajo ${ }^{113}$. Como la propia Djamila recuerda en una entrevista publicada en 2017, a su vuelta trabajó en centros sociales de acogida de poblaciones civiles y organización de reuniones de sensibilización de masas en previsión del referéndum del 1 de julio de1962, que llevó a la independencia de Argelia después de 132 años de ocupación ${ }^{114}$.

Por tanto, su situación no es aquella que le pronosticó Mohamed Khider: "pero señora, después de la independencia las mujeres deben volver a su cous-cous" ${ }^{115}$. Siguiendo el análisis de Neil MacMaster ${ }^{116}$, las militantes heroicas en tiempos de guerra, las muyahidinas, compartieron en gran parte la suerte de todas las mujeres teniendo que hacer frente a la marginación en la representación política, pero no volvieron simplemente al hogar, como se ha pretendido a menudo, sino que siguieron trayectorias complejas. Las ideas progresistas sobre las mujeres habían penetrado en el FLN, aunque de modo insuficiente. En un manual incautado al final de 1959, se propugna una política liberal de elección del matrimonio; el respeto mutuo entre la pareja; me-

111 Véase F. GRASSELLI, “Cuando la sangre de una muchacha es dicha y escuchada. Apuntes sobre testimonio y experiencia política de mujeres militantes en Djamila Boupacha (1962) de Simone de Beauvoir y Gisèle Halimi", Revista Nomadias, núm. 24, 2017, pp. 49-66.

112 S. de BEAUVOIR y G. HALIMI, Djamila Boupacha. Proceso a la tortura, cit., p. 19.

113 Véase, G. HALIMI, La lait de l'oranger, cit., pp. 354-356.

114 El Djeich. Revue mensuelle de l'Armée nationale populaire, cit., p. 53.

115 Véase J. CHINCHILLA, “La mujer argelina como elemento de negociación en la construcción de un nuevo poder político: de la independencia a la crisis del sistema de partido único", Relaciones Internacionales, núm. 27, octubre 2014-enero 2015, pp. 55-74, p. 66.

116 Véase N. MACMASTER, “Des révolutionnaires invisibles: les femmes algériennes et l'organisation de la Section des femmes du FLN en France métropolitaine", Revue d'histoire moderne et contemporaine, núm. 59 vol. 4, 2012, pp. 164-190. 
didas severas contra la violencia de género, y una cierta apuesta por la igualdad y la educación. Pero también encontramos programas con una visión natalista y con referencia a tradiciones y costumbres basadas en la autoridad masculina, ancladas en la idea de que "las mujeres, bastión de la argelinidad y madres de la nación, debían ser protegidas frente a una modernidad occidental corrosiva e inmoral"117, esencialmente ligada al colonialismo. Con el paso del tiempo, y el refuerzo tardío del código de familia de 1984, las promesas de emancipación de la mujer se fueron diluyendo y se fue comprobando la persistencia de estructuras patriarcales que implicaban una fuerte subordinación femenina y un estatus prácticamente de minoría de edad, bajo tutela del padre o del marido ${ }^{118}$, a gran distancia de la transformación deseada por muchas mujeres implicadas en la lucha de liberación de su país.

En general, según indica Maya Boutaghou, repensar el affaire Boupacha tantas décadas después de la independencia nos hace comparar una época llena de sueños de victoria a la Argelia de hoy. A este respecto, se pregunta si el hecho de que este asunto no sea tan conocido por los jóvenes de allí como el de Alleg no se deberá a que se trata de un asunto de mujeres ${ }^{119}$. La propia Simone de Beauvoir, años después de la independencia, en una entrevista de 1974, confiesa su decepción por Argelia, ya que el FLN no había logrado llevar la justicia a su país y en el proceso había traicionado a las mujeres argelinas ${ }^{120}$. A su juicio, en Argelia se conjuga el capitalismo de Estado, el nacionalismo y los valores reaccionarios que mantienen a la mujer en una situación deplorable ${ }^{121}$. Sin embargo, en el momento en que es alertada por Gisèle Halimi, la misma tarde de la desaparición, de lo sucedido con Djamila, la filósofa reacciona de una forma inesperada pues le dice que ha sido imprudente y que ellas no son quien para intervenir en la nueva Argelia. Melissa Ptacek considera que esta actitud es coherente con el pensamiento de Simone de Beauvoir, ya que no hay nada más arbitrario para ella que intervenir como extraño en un destino que no es el nuestro y los argelinos necesitan forjar su

117 Ibid., p. 180.

118 Véase C. FERNÁNDEZ, “Reflexiones en torno a las mujeres argelinas. Desde la colonización francesa (1830) hasta el siglo xxI", Revista de Antropología Experimental, núm. 15, 2015, pp. 159-170.

119 M. BOUTAGHOU, “Trois puissantes femmes: Simone de Beauvoir, Gisèle Halimi, Djamila Boupacha. Entre lutte anticoloniale et combat féministe", cit., p. 11.

120 Véase D. SALLENAVE, Simone de Beauvoir, contra todo y contra todos, pres. de S. Nair, trad. de M. Cordón y M. Embarek, Galaxia Gutenberg, Barcelona, 2010, p. 541.

121 Ibid., p. 529. 
propio camino hacia la libertad ${ }^{122}$. Gisèle Halimi discrepa y dice que en el fondo chocan sobre una cierta concepción de la razón de Estado. Además, ella es la que se lleva la peor parte, pues un comunicado del FLN, difundido en Túnez desde Francia, denuncia algunos días más tarde "la operación publicitaria intentada, con fines personales, por la abogada Gisèle Halimi, a propósito de la hermana Djamila Boupacha" ${ }^{123}$.

\subsection{Un horizonte que se abre}

Se manifiesta, así, la dificultad de conjugar el anticolonialismo, que Beauvoir y Halimi profesaron, con su lucha por la igualdad y la emancipación de la mujer en el marco del feminismo hegemónico. Como es sabido, el enfoque interseccional o el enfoque decolonial (negro, latinoamericano, islámico...) supusieron una dura crítica a ese feminismo que proyecta sus reivindicaciones a nivel global sin integrar la perspectiva de mujeres que pertenecen a otros contextos culturales y sociales. En este sentido, se ha planteado la necesidad precisamente de descolonizar el pensamiento feminista para hacerlo más sensible a la alteridad de la mujer, subordinada y discriminada en un sistema patriarcal, no sólo por razones de género, sino también por razones de clase y de raza ${ }^{124}$; categorías de opresión interrelacionadas que no pueden abordarse de forma separada, ya que la matriz de la dominación está en el cruce, que no es una mera suma de discriminaciones.

Un antecedente claro de esta posición alternativa frente a todo tipo de subalternidad la encontramos en Franz Fanon, uno de los fundadores del pensamiento poscolonial, cuyas obras Peau noire, masques blancs (1952) y Les damnés de la terre (1961) pueden considerarse el acta de nacimiento de una visión del mundo esencialmente crítica respecto a la realidad y el legado de la colonización. El prólogo al segundo de estos libros fue realizado por Jean Paul Sartre y tanto él como Simone de Beauvoir se beneficiarían de su amistad y de su influencia filosófica y política ${ }^{125}$. La última vez que estuvieron

122 Véase M. PTACEK, “Simone de Beauvoir's Algerian war: torture and the rejection of ethics", cit., p. 532.

123 G. HALIMI, La lait de l'oranger, cit., p. 357.

124 Véase F. VERGÈS. Le ventre des femmes. Capitalisme, racialisation, féminisme, Albin Michel, Paris, 2017 (formato Kindle).

125 Étienne BALIBAR señala la influencia de Beauvoir. Kojève y Sartre en la interpretación de Fanon de la dialéctica hegeliana del amo y del esclavo, "La construction du racismo", Actuel Marx, núm. 38, 2005/2, pp. 11-28, p. 25. 
juntos fue en el verano de 1961 en Roma, unos meses antes del fallecimiento de Fanon. Ya enfermo, Simone de Beauvoir recuerda en La fuerza de las cosas la energía con que seguía defendiendo la lucha, incluso violenta, para que el oprimido pueda recuperar su humanidad negada, como en el caso del FLN de Argelia, al que él pertenecía, pues "todos los colonizados eran sus hermanos y en la causa de los argelinos reconocía la suya" ${ }^{126}$. Después de fijarse en algunos aspectos de la biografía de Fanon, Simone de Beauvoir da una pincelada clara sobre su personalidad cuando afirma que "a su lado, la vida parecía una aventura trágica, a menudo horrible, pero de un precio infinito" ${ }^{127}$. De las largas conversaciones no se reseña ninguna reflexión compartida sobre el vínculo entre las reivindicaciones de la descolonización y las del feminismo, aunque ambas preocupaciones están latentes en la obra del filósofo martiniqués. En su ensayo L'Algérie se dévoile ${ }^{128}$, Fanon trata la cuestión de la liberación de la mujer, que él relaciona con al uso del velo (haik), visto, no necesariamente como signo de sumisión según el imaginario colonizador, sino como rasgo identitario frente a los valores del ocupante, técnica de camuflaje en la lucha y símbolo de resistencia, pues quitar el velo, violar, penetrar en la tierra ocupada, son manifestaciones de la expoliación que acompaña a todo dominio colonial ${ }^{129}$. Desde su punto de vista, en una Argelia independiente esas cuestiones irán perdiendo importancia pues ya no habrá que reforzar los hábitos tradicionales, como ya se empieza a constatar en el abandono del velo en el transcurso de la acción revolucionaria.

A pesar de la proximidad en su perspectiva anticolonialista, Simone de Beauvoir señaló que Fanon se había equivocado sobre el futuro de las mujeres tras la independencia. Sin embargo, algunos estudiosos de la obra de ambos autores, como Matthieu Renault ${ }^{130}$ o Annabelle Golay, sí que han visto una intuición paralela que puede apuntar hacia la interpenetración entre la lucha anticolonial y la feminista. Desde este punto de vista, la huella de Fanon permanecería en aquellos elementos de la obra beauvoiriana que, sin permitir en-

126 S. de BEAUVOIR, La fuerza de las cosas, cit., p. 688.

127 Ibid., p. 693.

128 Este ensayo forma parte del libro Sociología de una revolución, (el original en francés de 1959 se tituló $L^{\prime} A n V$ de la révolution algérienne), trad. de V. Flores, Ediciones Era, México, 1968.

129 Véase A. GOLAY, “Féminisme et postcolonialisme: Beauvoir, Fanon et la guerre d'Algérie", cit., pp. 409-414.

130 M. RENAULT, "Le genre de la race: Fanon, lecteur de Beauvoir", Actuel Marx, núm. 55, 2014/1, pp. 36-48. 
cuadrarla en una óptica interseccional o decolonial, prefigurarían algunos de sus rasgos. En este sentido, hay que tener en cuenta que, si bien en El segundo sexo la interiorización de la dependencia y la construcción social y cultural de la mujer como otro respecto al varón -su estatuto de Otra sin reciprocidad con el Mismo- presentan características propias pues se basan en un vínculo único, se trata para Beauvoir de fenómenos que en ciertos aspectos también se manifiestan en las clases y los pueblos oprimidos. En las últimas páginas de sus memorias, leemos estas reveladoras palabras: "Solo cuando los pieds noirs marcharon a Francia, y disputaron alojamientos y trabajos a los autóctonos, se hicieron impopulares: vimos nacer, justo a tiempo para reemplazar al antiguo, un nuevo racismo entre gente de la misma raza, como si siempre se necesitara Otro odiable para garantizar nuestra propia inocencia" ${ }^{131}$.

Djamila Boupacha simboliza ese Otro odiable que concentra diferentes situaciones de subalternidad. Su tortura señala el lugar de encuentro entre el predominio masculino, el racismo y las estrategias de la represión política. Annabelle Golay no duda en afirmar que "a la vez anticolonialista y feminista, la lucha de Beauvoir en favor de Djamila responde a la doble colonización, imperialista y patriarcal, de la que es víctima y que la coloca en situación de subalterna" ${ }^{132}$. Por ello, aunque el cruce, la interseccionalidad, no fueran pensados por Simone de Beauvoir, ni tampoco por Gisèle Halimi, en los términos de la discusión actual entre teorías o corrientes feministas, el proceso a la tortura de Djamila Boupacha fue para ambas -y seguramente aún de forma más clara en el caso de la abogada implicada de lleno profesionalmente en la causa anticolonialista- un primer atisbo de esta opresión cruzada que experimentan tantas mujeres en el mundo ${ }^{133}$. En este sentido, lo que ellas pretenden, como exige la orientación interseccional o decolonial, es aproximarse lo más posible a la perspectiva de una mujer perteneciente a otra realidad cultural y social. Así, el relato del proceso es un cuerpo a cuerpo con una musulmana que quiere liberarse a sí misma, pero ante todo liberar a su pueblo, del yugo de la dominación.

131 S. de BEAUVOIR, La fuerza de las cosas, cit., p. 723.

132 A. GOLAY, "Féminisme et postcolonialisme: Beauvoir, Fanon et la guerre d'Algérie", cit., p. 415.

133 Diane Perpich señala que, sin embargo, los textos de Beauvoir sobre el colonialismo rara vez son más que una nota a pie de página sobre su escritura y apenas aparecen en los escritos actuales sobre critical race theory, poscolonialismo o discusiones de interseccionalidad. D. PERPICH, "Beauvoir's Legacy to the Quartiers: The Changing Face of French Feminism,", cit., p. 495. 
El problema era cómo representar a Djamila Boupacha ante la opinión pública francesa, hacerla visible y reconocible como alguien con quien sintonizar pues el objetivo era la movilización pública, que difícilmente se conseguiría en Francia si era presentada como una militante radical, dispuesta a utilizar cualquier medio para lograr la liberación de su país. Según Heidi Brown, la descripción está diseñada para suavizar su imagen y aumentar su atractivo emocional, minimizando la acción de Boupacha como una mujer militante y adulta ${ }^{134}$. Sin coincidir por completo con este análisis, ya que de todo lo que llevamos dicho se deduce un perfil mucho más rico de la personalidad de Djamila -en el que destaca su convicción independentista, su determinación a la hora de denunciar a sus torturadores y su valentía al declararse víctima de una violación-, es verdad que en la descripción del proceso hay algunas resonancias de la imagen paternalista de una joven indefensa y vulnerable necesitada de protección. Además, como sugiere Julien Murphy, el discurso que prevalece, tanto en la parte redactada por Gisèle Halimi como en el prólogo de Simone de Beauvoir, es el discurso de la virginidad ${ }^{135}$.

Evidentemente es Djamila Boupacha la que está obsesionada por este tema, fruto del valor que se le concede en su cultura, y Halimi y Beauvoir lo certifican como no podría ser de otra forma. A lo largo de las páginas se incluye la descripción que hace Djamila del rito del matrimonio en Argelia y se subraya la importancia simbólica extraordinaria que se atribuye a la virginidad en las costumbres nupciales de su país: “Interrogada por los médicos acerca del sentido y el valor de la virginidad, Djamila es absoluta: es un tótem, una magia" 136 . En sus encuentros con su abogada siempre la misma pregunta, ¿tú crees que todavía soy virgen?, y las mismas confidencias: "Puesto que no he conocido a ningún hombre, quizá la botella no me ha estropeado del todo" 137; " para nosotros no es lo mismo que para vosotros, la chica tiene que ser virgen" ${ }^{138}$. También en el prólogo de Simone de Beauvoir se destaca que Djamila había sufrido una "desfloración traumática" ${ }^{139}$ y en el artículo de Le Monde había constatado que "Djamila era virgen". La cuestión es que,

134 Véase H. BROWN, "From Sensation to Representation: The Torture of Djamila Boupacha During the Algerian War", Women in French Studies, vol. 26, 2018, pp. 83-95, pp. 87-88. 286.

135 J. MURPHY, "Beauvoir and the Algerian War: Toward a Postcolonial Ethics", cit., p.

136 S. de BEAUVOIR y G. HALIMI, Djamila Boupacha. Proceso a la tortura, cit., p. 147.

137 Ibid., p. 59.

138 Ibid., p. 85.

139 Ibid., p. 11. 
si bien Halimi y Beauvoir lo que quieren es reflejar fielmente la experiencia vivida por Boupacha con el significado que ella le otorga, la forma en que dan cuenta de la intensidad de su temor por la posible pérdida de la virginidad contrasta de algún modo con las consideraciones de ambas autoras en sus respectivas memorias sobre el tabú o el mito de la virginidad. Gisèle Halimi recuerda que en su juventud en Túnez "la virginidad y sus tabúes invisten al hombre de un derecho de vida o muerte en caso de transgresión" ${ }^{140}$, y, más tarde, se refiere a la virginidad, la fecundidad y la maternidad como "tabúes" del mundo del que procede y confiesa que "recibió la refutación de estos mitos como el milagro de (su) identidad revelada" ${ }^{141}$. Por su parte, en El segundo sexo Simone de Beauvoir explica el origen del término "desfloración" y analiza el carácter ambivalente, entre el miedo y el deseo, del mito de la virginidad, que se exalta y se exige cuando el hombre considera a su esposa su propiedad personal.

Lo que sorprende sobre todo es que, a pesar de estas opiniones, como senala Judith Surkis, se movilice esta figura para el argumento político ${ }^{142}$. En la misma línea, las referencias de Djamila Boupacha a la castidad en las relaciones entre los miembros del FLN, guiadas por un sentimiento fraternal ${ }^{143}$, aparecen reflejadas en el texto sin introducir ninguna valoración, aunque es evidente la distancia cultural: "Sabes, aquí no es lo mismo que en Francia; los hermanos y las hermanas pueden estar en la misma habitación y no tocarse... Nosotros tenemos un tribunal muy severo para los que no respetan a las chicas" ${ }^{\prime 14}$. La intención del comentario es evitar los equívocos a que podría dar lugar el descubrimiento de que su habitación sirvió de escondite de guerrilleros.

140 G. HALIMI, La lait de l'oranger, cit., p. 107.

141 Ibid., p. 351.

142 J. SURKIS, "Ethics and Violence. Simone de Beauvoir, Djamila Boupacha and the Algerian War", cit., p. 44.

143 Z. REZVANTALAB analiza las representaciones de la guerra en obras escritas por mujeres de Irán y Argelia y, en especial en las novelas Dâ de Azam Hosseini y La Grotte éclatée de Yamina Méchakra. En la misma línea que Djamila Boupacha, "destaca el uso frecuente en las dos novelas de las expresiones hermano y hermana bajo la influencia de la cultura de las comunidades musulmanas. Con el objetivo de reproducir el ambiente de solidaridad, de respeto, de confianza que reinaba entre los y las combatientes, las dos escritoras recurren a este vocabulario de la sororidad y de la fraternidad en sus relatos de la guerra", "Écrire le combat au féminin: Regard sur la représentation de la guerre à travers la littérature féminine en Iran et en Algérie", Actes du colloque Dire la guerre dans la fiction contemporaine de langues française et persane, Les Presses de l’Université de Téhéran, 2016, pp. 139-148, p.148.

144 S. de BEAUVOIR y G. HALIMI, Djamila Boupacha. Proceso a la tortura, cit., p. 58. 
Y, en efecto, en la prensa se utilizó la presencia de hombres en su habitación como sospecha de promiscuidad y prueba de que su afirmación de sufrir penetración vaginal bajo tortura era infundada e irrelevante. Además, fue llamada "la colocadora de bombas" o "la mecanógrafa-bomba-retardada" y criticada por vestir coquetamente "al gusto del verano", por llevar su impertinencia al extremo de peinarse "a la cretense", y por una actitud escandalosa en general junto a su abogada -que tampoco se libró de la misoginia de la prensa- al olvidar ambas su graciosa feminidad y su gentileza convirtiéndose en pasionarias ${ }^{145}$. Como muy bien indica Vanessa Codaccioni, la retórica utilizada es la propia de los asuntos sexuales, la del posible consentimiento o la provocación femenina para desacreditar su acusación ${ }^{146}$. La cuestión se planteó de forma clara: si esa "muchacha musulmana" recibía a hombres en su casa, "qué pensar de su querella contra los militares que, según dice, abusaron de ella". Por ello, con doliente ironía, Halimi añade: "Efectivamente, ¿por qué iba a quejarse Djamila de haber sido empalada con una botella si había consentido en albergar -quizás incluso en su habitacióna maquisards argelinos?" 147

Los tabúes sexuales como el de la virginidad, a pesar de que Djamila era la primera en asumirlos, fueron utilizados en su contra. Demostrar que era virgen antes de sufrir la tortura resultaba un contra argumento decisivo, evidentemente no porque desde el punto de vista de Gisèle Halimi la agresión sexual en sí misma fuera menos censurable en caso contrario, sino porque tanto a nivel interno en Francia, y en la mayor parte de países, como a nivel internacional según el Cuarto Convenio de Ginebra de 1949 (art. 27), la violación era considerada un atentado al honor de la mujer, que, además, ni siquiera se encontraba entre las infracciones más graves. En la mentalidad de la época, si Djamila no era virgen, lo que, dado que era una mujer soltera, equivalía a decir que no había respetado las buenas costumbres estrictas en su país, el reclamo de la violación perdía fuerza porque su honor y pudor ya habían sido puestos en entredicho. Faltaban todavía dos décadas para que, gracias en gran parte a la reivindicación feminista del control sobre el propio cuerpo tan activa en Gisèle Halimi y Simone de Beauvoir, el bien jurídico protegido en la política criminal contra la violación dejara de estar ligado a

\footnotetext{
145 Ibid., pp. 95-98.

146 Véase V. CODACCIONI, “(Dé)Politisation du genre et des questions sexuelles dans un procès politique en contexte colonial: le viol, le procès et l'affaire”, cit., p. 42.

147 S. de BEAUVOIR y G. HALIMI, Djamila Boupacha. Proceso a la tortura, cit., pp. 99-100.
} 
la honestidad de la mujer, a las buenas costumbres, a la honorabilidad de la familia y a la filiación, para pasar a ser un atentado a la libertad sexual de las personas que, además, puede materializarse, como en nuestro caso, a través de la introducción de objetos.

En aquel momento el caso no podía presentarse propiamente como un asunto sexual. La denuncia no era por violación sino por secuestro y tortura, que sí eran delitos contra la libertad, la integridad y la dignidad de las personas y de mayor gravedad. Ahora bien, todo el itinerario del proceso ha mostrado que el hecho de que la tortura fuera por violencia sexual -violación y el resto de abusos sobre la anatomía femenina antes mencionados- no era un hecho indiferente, sino, muy al contrario, uno de los motivos que hizo despertar la conciencia y acción colectivas a favor de Djamila, lo que proporciona pistas para interpretar el caso en las coordenadas de una militancia feminista todavía en ciernes. En este sentido, en una entrevista en 2008, Gisèle Halimi comenta la diferencia en la percepción del tema entre varones y mujeres, incluso dentro del Comité en defensa de Djamila Boupacha: "La cuestión de la violación ha sido más que tabú entre los intelectuales progresistas [...] Los hombres que formaban parte de nuestro comité la tenían en cuenta, pero no de la misma forma. El problema eran las torturas, las torturas de una manera más general [...] Les parecía que se teatralizaba un poco la historia, no querían hablar de ello [...] No creo que el hecho de que ella haya sido violada fuera vivido por ellos como lo vivimos nosotras las mujeres, como algo específico y abominable" ${ }^{\prime 14}$. Vemos, por tanto, que, como insiste Codaccioni, "Gisèle Halimi trató de imponer una lectura genrée del proceso insertando en su estrategia jurídica la dimensión sexuada y sexual de la violencia sufrida por su clienta" ${ }^{149}$, aunque no pudiera ser esta la causa principal de la querella contra sus torturadores, ya que no podía apoyarse en textos jurídicos que consideraran la violencia sexual como acto de tortura.

De este modo, si bien Halimi se encontró con impedimentos insalvables, el asunto Boupacha es un importante precedente de un cambio sustancial de perspectiva, que a nivel global se materializaría en los años noventa en las resoluciones de los dos tribunales penales internacionales ad hoc para la ex Yugoslavia y Ruanda, constituyendo un gran avance del derecho interna-

148 Véase V. CODACCIONI, “(Dé)Politisation du genre et des questions sexuelles dans un procès politique en contexte colonial: le viol, le procès et l'affaire", cit., p. 43.

149 Ibid., p. 44. 
cional hacia una justicia de género ${ }^{150}$. Gracias a la experiencia de estos tribunales y a diferentes voces dentro del movimiento feminista, a partir del libro de Susan Brownmiller Against Our Will: Men, Women, and Rape ${ }^{151}$ (1975), fue saliendo a la luz algo que se había dado siempre a lo largo de la historia pero que no había sido objeto de reflexión: la utilización, e incluso justificación, de la violencia sexual como un acto de poder y de control fundamental para la dominación patriarcal de las mujeres. A partir de ahí, las agresiones sexuales dejan de estar confinadas en el ámbito privado para ser vistas como un problema político con relevancia jurídica. En el caso concreto de la guerra de Argelia, el uso de la tortura contra las mujeres argelinas pretendía mantener la opresión colonial a través de una sumisión basada en elementos sexuales y raciales ${ }^{152}$. En palabras de Françoise Vergès: “La utilización de la violación y de la tortura pertenece a la historia misma del colonialismo; la colonización era una política de desposesión, de apropiación de las tierras y de los cuerpos, de transformación de los cuerpos en objetos; la utilización sistemática de la violación y de la tortura durante la guerra era la continuación de las políticas de desposesión" ${ }^{153}$. El testimonio de Henry Alleg en el libro de Halimi y Beauvoir pone el énfasis en que "los gritos de Djamila derrumban los nuevos muros del silencio y de la hipocresía", y atestiguan que "la tortura, -"la forma más insultante y más bestial de desprecio" - solo podrá cesar con la guerra colonial de la cual es el fruto envenenado" ${ }^{154}$. También Josette Audin, la viuda del joven matemático asesinado en El Biar, señala que la tortura es una tara del régimen colonial, que solo acabará con el fin del régimen ${ }^{155}$. Y

150 En las últimas dos décadas, la jurisprudencia tanto de la Corte Interamericana de Derechos Humanos como del Tribunal Europeo de Derechos Humanos ha ido configurando de forma paralela y progresiva la violencia sexual como un crimen de tortura. Véase M. MARTÍN e I. LIROLA “El diálogo jurisdiccional interregional en la investigación y sanción de la violencia sexual", Araucaria. Revista Iberoamericana de Filosofía, Política, Humanidades y Relaciones Internacionales, núm. 40, 2018. pp. 511-575. Por otra parte, el Manual para la investigación y documentación eficaces de la tortura y otras penas o tratos crueles, inhumanos o degradantes, conocido como el Protocolo de Estambul, adoptado por el Alto Comisionado de las Naciones Unidas para los Derechos Humanos en el año 2000, en su capítulo V, apartado D8, especifica todo lo referente a la tortura sexual, incluida la violación.

151 S. BROWNMILLER, Contra nuestra voluntad: Hombres, Mujeres y Violación, trad. S. Constante, Planeta, Barcelona, 1981.

152 Véase R. BRANCHE, "Des viols pendant la guerre d'Algérie”, Vingtième Siècle. Revue d'histoire, núm.75, 2002/3, p. 129.

153 F. VERGÈS. Le ventre des femmes. Capitalisme, racialisation, féminisme, cit.

154 S. de BEAUVOIR y G. HALIMI, Djamila Boupacha. Proceso a la tortura, cit., pp. 237-242. 155 Ibid., pp. 243-244. 
en el mismo sentido se expresan el padre Chenu, André Philip y otros colaboradores del libro, entre los que merece una mención especial el general Bollardière, uno de los pocos militares franceses que, como destaca Tzvetan Todorov, denunciaron públicamente el "espantoso peligro" que representa para una nación la práctica generalizada de la tortura ${ }^{156}$.

El 11 de octubre de 2001 en Le Monde, la periodista Florence Beaugé ${ }^{157}$ firma un interesante y documentado artículo en el que, como resultado de entrevistas a soldados que participaron en la guerra entre 1954 y 1962, llega a la conclusión de que el ejército francés violó de forma masiva a las mujeres durante la guerra de Argelia. A estos efectos, la historiadora Claire MaussCopeaux indicó que dos factores explican que este fenómeno tuviera un alcance tan amplio: el ambiente de extremo racismo hacia la población musulmana y el tipo de guerra que llevó a cabo el ejército francés, confrontado a una guerrilla que le obligaba a dispersarse y a dejar un amplio margen de maniobra a pequeños jefes que, aislados en el terreno, podían atribuirse el derecho a decidir sobre la vida y la muerte de la población. Además, uno de los soldados entrevistados intenta justificarse diciendo: "Hay que trasladarse a la situación del momento: teníamos veinte años, los argelinos eran considerados como infrahumanos y las mujeres caían en una categoría todavía inferior, peor que perros". Benoist Rey, que explicó su experiencia como enfermero en Argelia en el libro Les Égorgeurs ${ }^{158}$, declara que los oficiales permitían la violación ya que simplemente se trataba de mujeres y árabes. Henri Pouillot, autor de La

156 Véase T. TODOROV, “La tortura durante la guerra de Argelia”, Letras libres, núm. 43, 2002 , pp. 12-18. Todorov se basa en conversaciones con excombatientes franceses para intenta entender cómo la tortura pudo llegar a ser una práctica omnipresente en la guerra de Argelia, aunque es bien consciente del riesgo de justificar este fenómeno al tratar de explicarlo. Sobre las estrategias discursivas de justificación de la tortura me remito a mis trabajos anteriores: E. BEA, “Tortura, ¿nunca más? Reflexiones ante el riesgo posthumanista” en J. BALLESTEROS y E. FERNÁNDEZ (coord.), Biotecnología y Posthumanismo, Thomson/Aranzadi, Madrid, 2007, pp. 109-138; Id., “Tortura” en M. LA TORRE, M. LALATTA, A. SCERBO (ed.), Questioni di vita o morte, Etica pratica, bioetica, filosofia del diritto, Giappichelli, Torino, 2007, 292-313; Id., "La reapertura del debate sobre la tortura en el marco del Estado constitucional" en E. FERNANDEZ et al. (ed.) Teoría de la justicia y derechos fundamentales. Estudios en homenaje al profesor Gregorio Peces-Barba, vol. 3, 2008, pp. 167-191; Id. "Il divieto della tortura rimesso in discussione", Ragion pratica, núm. 32, 2009, pp. 133-152.

157 F. BEAUGÉ, "Le tabou du viol des femmes pendant la guerre d'Algérie commence à être levé". Véase también Algérie, une guerre sans gloire: Histoire d'une enquête (Documents, Actualités, Société), Calmann-Lévy, Paris, 2005.

158 B. REY, Les Égorgeurs, Éditions de Minuit, Paris, 1961.

ISSN: 1133-0937

DERECHOS Y LIBERTADES

DOI: https://doi.org/10.20318/dyl.2021.6102

Número 45, Época II, junio 2021, pp. 57-98 
Villa Sesini ${ }^{159}$, establece la diferencia entre dos tipos de violaciones, las que se cometían durante la tortura, como un método para que la detenida hablase, y las más numerosas, "de confort", que se perpetraban sólo para desahogarse. Gisèle Halimi coincide en la referencia a estas dos modalidades de la tortura sexual y subraya que durante los interrogatorios se apunta a la aniquilación total de la víctima. El objetivo de la tortura es menos hacer hablar que hacer entender quien tiene el poder y, en el caso de la tortura por violación, el deseo es menos sexual que voluntad de posesión y de humillación. La obtención de información es una ficción interna a la propia estructura del tormento: “El mandato del torturador no es un acto lingüístico [...] Es una pregunta a la que solo corresponde el sí" 160 . Boupacha es un ejemplo: "En uno de estos interrogatorios forzados, Djamila confiesa haber puesto la bomba en la Brasserie des Facultés. En el Coq Hardi, en otros establecimientos, en todas partes... Los inspectores están locos de rabia. Djamila parece tomarles el pelo: se acusa de crímenes cuyos culpables han sido ya condenados" ${ }^{161}$.

Dentro de la lógica perversa de la tortura, el torturador siente el placer -a veces psicológico y siempre político- de tener un poder infinito sobre el cuerpo de otro. Siguiendo a Elaine Scarry en su célebre libro The Body in Pain ${ }^{162}$, el dolor continuo e intenso que el verdugo inflige al prisionero destruye su representación del mundo. Objetos familiares, como en este caso una simple botella o una bañera, o lugares familiares, como una habitación -“el ruido de las llaves en la cerradura era, para Djamila, el temor a un nuevo interrogatorio" 163 - se convierten en los instrumentos con los que los torturadores causan dolor. El mundo está roto, alienado en un universo hostil. Según Julián Marrades: “La tortura exacerba la percepción de división interna entre el yo y el cuerpo que es consustancial al dolor, presentándola a los ojos del sufriente como una lucha a muerte entre él mismo, como sujeto moral, y su propio cuerpo, como fuerza disgregadora de su yo" ${ }^{\prime 64}$. Para Simone

159 H. POUILLOT, La Villa Sesini, Tirésias, Paris, 2001.

160 M. LA TORRE y M. LALATTA COSTERBOSA, ¿Legalizar la tortura? Auge y declive del Estado de Derecho, trad. de F. J. Ansuátegui, Tirant lo Blanch, Valencia, 2018, p. 152.

161 S. de BEAUVOIR y G. HALIMI, Djamila Boupacha. Proceso a la tortura, cit., p. 43.

162 Oxford University Presse, New York, 1987.

163 S. de BEAUVOIR y G. HALIMI, Djamila Boupacha. Proceso a la tortura, cit., p.148.

164 J. MARRADES, "La vida robada. Sobre la dialéctica de dolor y poder en la tortura", Pasajes. Revista de pensamiento contemporáneo, núm. 17, 2005, pp. 29-38, p. 30. Véanse también en este número: S. ŽIŽEK, "Sobre terrorismo y tortura”, pp. 21-27 y J. de LUCAS, "Un cáncer que crece: tortura y democracia", pp. 41-46. 
de Beauvoir, somos constitutivamente libres, pero la libertad se encarna en situaciones, y hay situaciones tan constrictivas que dificultan nuestro ejercicio de la transcendencia hasta obligarnos a caer en la inmanencia, en la facticidad; y aquí es donde reside el núcleo de la opresión. En este sentido, no hay mayor opresión que la de la tortura, pues no podemos imaginar una situación de mayor constricción, nada que nos cosifique más, que nos reduzca más a la condición de $\operatorname{cosas}^{165}$.

La inexorabilidad de la tortura condujo a Djamila, como ella misma recuerda en la entrevista de 2017, a firmar sus confesiones aceptando todas las acusaciones a fin de encontrar un poco de descanso en prisión y escapar del tormento. Pero no por ello deja de afirmar que su coraje y su fe le permitieron superar la violencia que había sufrido durante treinta y tres días, y que las lágrimas de su padre "tuvieron el efecto de galvanizar y acrecentar su resistencia frente a seres que habían perdido todo rastro de humanidad" 166. La relación con su abogada y la proyección de esta relación al exterior, al comité creado en su defensa, al mundo que conoce su historia, fue también un factor central para resistir. La narración de las vejaciones y maltratos sufridos se convierte en un acto comunicativo que le proporciona la posibilidad de expresarse, que da a su dolor un lugar en el mundo y, con ello, produce una cierta inversión del proceso de tortura. No olvidemos que, gracias a su sintonía con Gisèle Halimi, Djamila Boupacha fue la primera militante detenida que se atrevió a denunciar públicamente su violación. Traumatizada por la pérdida violenta de su virginidad, fue capaz de exponerse, de sacar a la luz lo más privado e incomunicable, lo que ocurre en el interior de su propio cuerpo, desvelando, así, "una vivencia destinada a no ser dicha"167, a permanecer oculta.

Volver la mirada de nuevo a la visita del comité a Maurice Patin, en la que el magistrado argumentó que la violencia infligida a las mujeres no era el auténtico suplicio, puede ayudarnos a concluir este recorrido por el asunto Boupacha. Como se recordará, al final del encuentro, el presidente de la Comisión de Salvaguardia de las Libertades y los Derechos Individuales

165 Simone de Beauvoir se refiere a la tortura tanto en el ensayo Ojo por ojo (1946), incluido en El existencialismo y la sabiduría de los pueblos (trad. de H. Pons, Edhasa, Barcelona, 2009), como en la novela Las bellas imágenes (1966) (trad. de J. Blanco, Edhasa, Barcelona, 2018).

166 Entrevista en El Djeich. Revue mensuelle de l'Armée nationale populaire, cit., p. 53.

167 F. GRASSELLI, "Cuando la sangre de una muchacha es dicha y escuchada. Apuntes sobre testimonio y experiencia política de mujeres militantes en Djamila Boupacha (1962) de Simone de Beauvoir y Gisèle Halimi", cit., p. 51. 
dijo que Djamila se creía que era Juana de Arco; una referencia que muestra claramente que la transgresión de las normas de género y la resistencia al dominio colonial están en el corazón del problema. Djamila Boupacha había vulnerado las reglas impuestas por las relaciones de poder patriarcales y coloniales. La tortura practicada sobre su cuerpo es una venganza contra las mujeres que alteran la posición jerárquica que les ha sido asignada. Como escribe Fabiana Grasselli: “Djamila será construida en la textualidad del relato como un símbolo capaz de hacer visible que las mujeres reciben la tortura de la violación como acto moralizante y disciplinador, no sólo por su pertenencia a una organización independentista enfrentada al régimen, sino también porque deben ser castigadas por su ingreso a un espacio vedado a ellas, al territorio de la práctica política, al lugar de la rebeldía" ${ }^{168}$. La prueba es que la intimidación y la violencia contra las mujeres, con características sexuales evidentes, fue creciendo a medida que crecía el reconocimiento de la participación femenina en la guerra.

Las señales en el cuerpo de Djamila Boupacha advierten de los riesgos de traspasar los límites establecidos por las relaciones de género, de raza y de clase, pero también indican un horizonte de libertad personal y de liberación colectiva frente al yugo de cualquier tipo de opresión. Por eso dijimos al principio de este recorrido, y es lo que se ha intentado mostrar de la mano de Gisèle Halimi, Simone de Beauvoir y el resto de mujeres del comité, que ese cuerpo marcado por la violencia sexual, aunque no exento de implicación en actos violentos, puede ser visto, no solo como representación de la represión, sino también como símbolo de la resistencia política.

\author{
Emilia Bea Pérez \\ Facultad de Derecho \\ Universidad de Valencia \\ Avda. dels Tarongers, s/n. Edificio Occidental \\ 46071 Valencia \\ e-mail:Emilia.Bea@uv.es
}

168 Ibid., p. 62. 